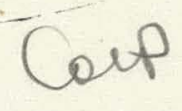

AMES LABORATORY

\author{
Iowa State University
}

Ames, Iowa

AEC Contract No. W-7405-eng-82

\begin{abstract}
This report was prepared as an account of Government sponsored work. Neither the United States, nor the Commission, nor any person acting on behalf of the Commission:

A. Makes any warranty or representation, expressed or implied, with respect to the accuracy, completeness, or usefulness of the information contained in this report, or that the use of any information, apparatus, method, or process disclosed in this report may not infringe privately owned rights; or

B. Assumes any liabilities with respect to the use of, or for damages resulting from the use of any information, apparatus, method, or process disclosed in this report.

As used in the above, "person acting on behalf of the Commission" includes any employee or contractor of the Commission, or employee of such contractor, to the extent that such employee or contractor of the Commission, or employee of such contractor prepares, disseminates, or provides access to, any information pursuant to his employment or contract with the Commission, or his employment with such contractor.
\end{abstract}

\title{
KINETICS OF METHYL IODIDE-IODINE EXCHANGE IN A SHOCK TUBE
}

by

Quther Allen Jay Kassman

Ph. D. Thesis, February 1969

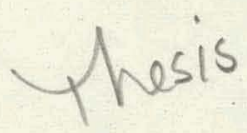




\section{DISCLAIMER}

This report was prepared as an account of work sponsored by an agency of the United States Government. Neither the United States Government nor any agency Thereof, nor any of their employees, makes any warranty, express or implied, or assumes any legal liability or responsibility for the accuracy, completeness, or usefulness of any information, apparatus, product, or process disclosed, or represents that its use would not infringe privately owned rights. Reference herein to any specific commercial product, process, or service by trade name, trademark, manufacturer, or otherwise does not necessarily constitute or imply its endorsement, recommendation, or favoring by the United States Government or any agency thereof. The views and opinions of authors expressed herein do not necessarily state or reflect those of the United States Government or any agency thereof. 


\section{DISCLAIMER}

Portions of this document may be illegible in electronic image products. Images are produced from the best available original document. 
KINETICS OF METHYL IODIDE-IODINE EXCHANGE IN A SHOCK TUBE

by

Allen Jay Kassman

A Dissertation Submitted to the

Graduate Faculty in Partial Fulfillment of

The Requirements for the Degree of

DOCTOR OF PHILOSOPHY

Major Subject: . Physical Chemistry

Approved:

$\frac{\text { Den } \frac{1}{\text { Mata }}}{\text { In Charge of Major Work }}$

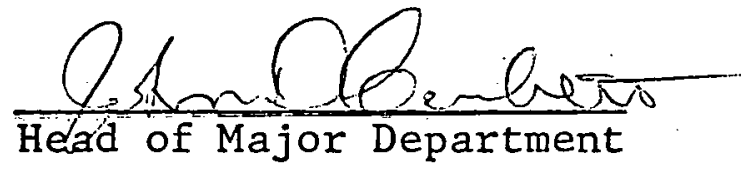

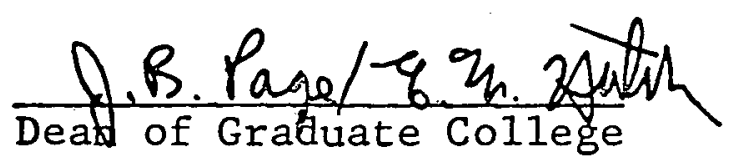

Iowa State University

Ames, Iowa

February 1969 
TABLE OF CONTENTS

ABSTRACT

Page

iv :

I. INTRONUCTION 1

A. Nature and Purpose of the Investigation 1

B. The Shock Tube 6

C. Symbolism 8

II. SHOCK TUBE THEORY: EXPERIMENTAL DEVELOPMENT 11

A. Fundamental Shock Tube Behavior 11

B. Shock Wave Generation. 14

C. Quenching Technique 17

D. Measurement of Shock Parameters 18

E. Measurement of Progress of Reaction . 22

III. SHOCK TUBE THEORY: THEORETICAL DEVELOPMENT 23

A. Ideal Shock Tube Theory 23

B. Application to Real Gases with Chemical - 46 Reaction

IV. EXPERIMENTAL 52

A. Chemicals 52

B. Apparatus 53

C. Procedures 61

V. CALCULATIONS 65

A. Determination of Reaction Parameters $\quad 65$

B. Treatment of Isotopic Exchange 72

VI. RESULTS AND DISCUSSION 80

$\begin{array}{ll}\text { VII. SUMMARY } & 89\end{array}$

$\begin{array}{ll}\text { VIII. LITERATURE CITED } & 90\end{array}$

$\begin{array}{ll}\text { IX. ACKNOWLEDGMENT } & 94\end{array}$

X. APPENDIX $\quad 95$ 
Allen Jay Kassman

ABSTRACT

The homogeneous gas phase isotopic exchange of methyl iodide and iodine was studied in the single-pulse shock tube in the temperature range
$870-1105^{\circ} \mathrm{K}$. The exchange was monitored by tagging molecular iodine with I tracer. The observed rate of exchange was in agreement with the following me chanism:

$$
\begin{aligned}
& \mathrm{M}+\mathrm{I}_{2} \underset{\mathrm{r}}{\stackrel{\mathrm{d}}{\rightleftarrows}} 2 \mathrm{I}+\mathrm{M}, \\
& \mathrm{I}+\mathrm{CH}_{3} \mathrm{I} \stackrel{\mathrm{I}}{\stackrel{\mathrm{T}}{2}} \mathrm{CI}_{3}+\mathrm{I}_{2},
\end{aligned}
$$

where $M$ is the inert carrier gas, in the present case argon. The rate constants $k_{d}$ and $k_{r}$ were taken from the shock tube data of other workers on the three-body recombination rate. The isotopic exchange reaction allowed a determination of $k_{1}$ as follows:

$$
k_{1}\left(\frac{c c}{\text { mole-sec }}\right)=10^{13.9} \exp \left(\frac{-20.0 \mathrm{kcal}}{\mathrm{RT}}\right)
$$

This value of $k_{1}$ is slightly lower than its determination by other workers as the rate determining step of the reaction

$$
\mathrm{CH}_{3} \mathrm{I}+\mathrm{HI} \rightleftarrows \mathrm{CH}_{4}+\mathrm{I}_{2}
$$

It is, however, within the experimental error for a more acceptable value of the Arrhenius factor of 14.1-14.2.

*USAEC Report IS-T-274. This work was performed under contract W-7405-eng-82 with the Atomic Energy Commission. 


\section{INTRODUCTION}

A. Nature and Purpose of the Investigation

The gas phase reactions of the halogens have been of interest since the early work of Bodenstein $(1,2,3)$. In 1934 Ogg (4) was the first investigator to study the reactions of the alkyl iodides with hydrogen iodide. Shortly thereafter Ogg and Polanyi (5), and Clark, Pritchard, and TrotmanDickenson (6) studied the exchange of iodine with the alkyl iodides. Some of these reactions served as classic examples of the elucidation of reaction mechantsms.

In 1961 Benson and O'Neal (7) and Sullivan (8) predicted, on the basis of Ogg's data for the reaction of methyl iodide and hydrogen iodide (4), that the results could well be interpreted in terms of an atomic mechanism rather than Ogg's mechanism. Ogg had suggested a combination of a bimolecular reaction of methyl iodide with iodine and a unimolecular dissociation of the iodide into a methyl radical and iodine atom. Flowers and Benson (9) repeated the experiments and demonstrated the atomic mechanism conclusively. Similarly, it was believed in some circles that the binolecular mechanism proposed by Bodenstein for the formation of hydrogen iodide from iodine and hydrogen could be discarded in favor of an atomic 
mechanism.. The recent study by Sullivan (10), although unable to discriminate between two alternative atomic mechanisms, leaves little doubt of the invalidity of Bodenstein's mecharism. At this point it appeared obvious that perhaps a reexamination of the isotopic exchange reactions was in order.

The work of Ogg and Polanyi (5) was undertaken to determine whether a free atom substitution proceeds by an $\mathrm{S}_{\mathrm{N}} 2$ mechanism with optical inversion of the alkyl halide molecule. Sec-buty 1 iodide was chosen for the experiment because it is the simplest and most stable of the optically active iodides. Low temperature work in the region $150-180^{\circ} \mathrm{C}$ gave rates that were sharply dependent on the surface-volume ratios of the reaction vessel. This heterogeneous reaction had a low activation energy of approximately $8000 \mathrm{cal} . / \mathrm{mole}$. Since the homogeneous exchange was expected to have a considerably higher activation energy the temperature of the experiments. was raised in hope of having the homogeneous reaction predominate. This did not solve the problem, and it was then decided to begin the experiment in the absence of iodine and raise the temperature to the point where decomposition of the sec-butyl iodide provided iodine for the racemization. The results appeared to confirm the $S_{N} 2$ mechanism and gave an 
activation energy of about $32.2 \mathrm{kcal} . / \mathrm{mole}$ for the inversion step.

In 1954, Clark, Pritchard, and Trotman-Dickenson (6) attempted to restudy the problem using methyl iodide and iodine tagged with radioactive $I^{131}$. It was expected that the increased stability of methyl iodide over the sec-butyl iodide would allow studies of the system at much higher temperatures where the homogeneous exchange would predominate without the onset of decomposition. However, even at temperatures up to $375^{\circ} \mathrm{C}$ curvature on the Arrhenius plot remained. A straight-line Arrhenius plot for the heterogeneous exchange. resulted from packing the reaction vessel. These results are illustrated in Figure 1. The dashed line indicated that the activation energy for the homogeneous exchange was greater than the $32.2 \mathrm{kcal} . / \mathrm{mole}$ reported by Ogg and Polanyi. However, the curvature of the dashed line suggested that the homogeneous exchange could not be isolated at temperatures at which methyl iodide is stable. The apparent activation energy of the heterogeneous reaction, which was independent of iodine concentration, was given as $17 \mathrm{kcal} / \mathrm{mole}$.

Schmied and Fink (11) are the only investigators to restudy this problem up to the present date. These workers carried out the exchange of methyl iodide with tagged iodine 


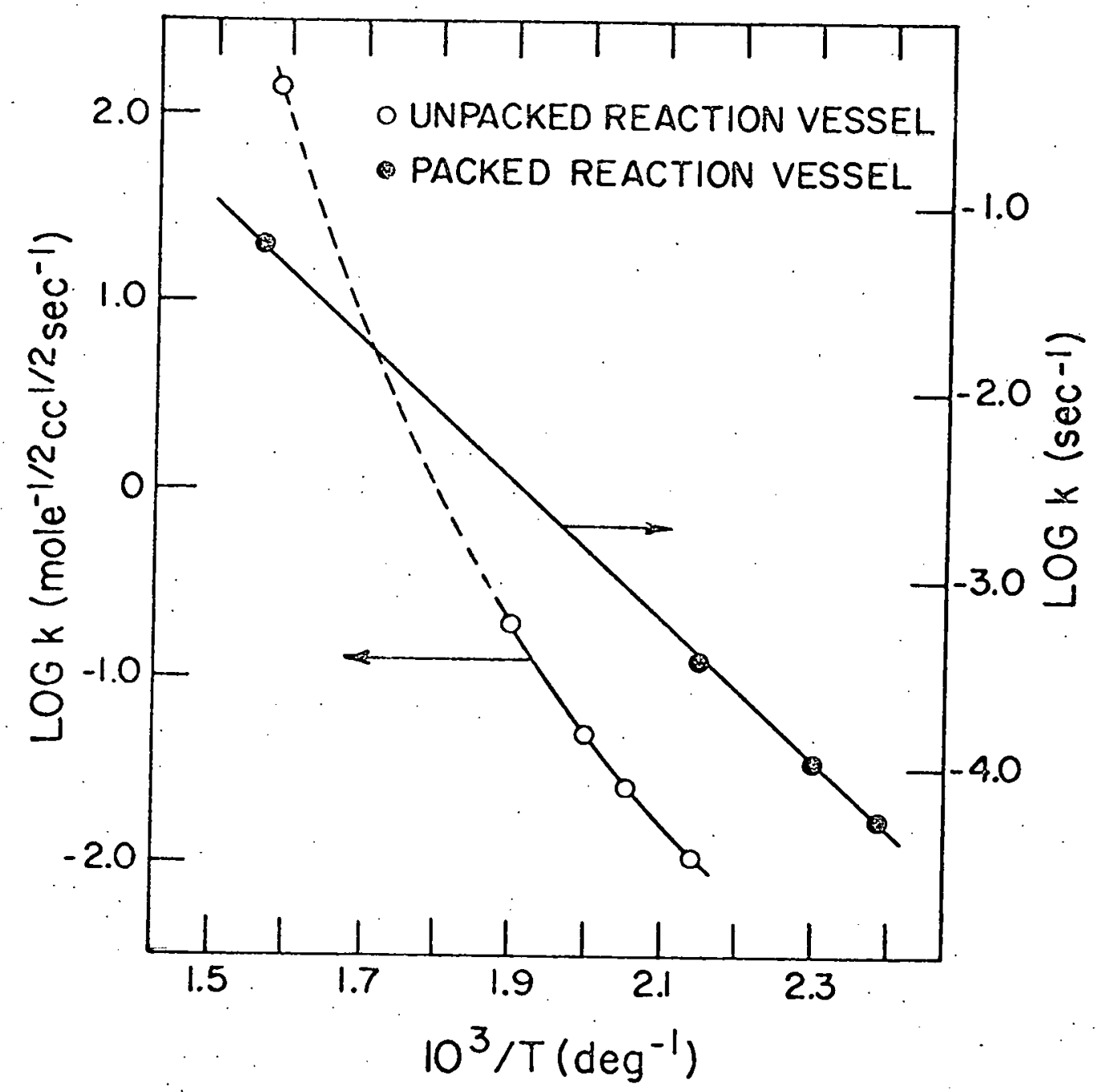

Figure 1. Arrhenius plots of the $\mathrm{CH}_{3} \mathrm{I}-\mathrm{I}_{2}$ exchange as studied by Clark et al. (6) 
in the temperature range $60-140^{\circ} \mathrm{C}$. By using various preheated surfaces they claimed to have raised the activation energy of the heterogeneous surface reaction to the point where the homogeneous exchange predominated. With this technique they concluded that the homogeneous exchange was bimolecular, with an activation energy of $9000 \mathrm{cal} / \mathrm{mole}$, and proposed the possibility of a four-center intermediate. They further suggested that the rate expression found by Clark et al. (6), which was half order in iodine, was an intermediate value between zero order for the surface reaction and first order for the bimolecular mechanism. They also suggested that the process in the high temperature region was not a free atom reaction but a free radical reaction that proceeds by attachment of the methyl radicals to the walls of the reaction vessel. As evidence for the simultaneous existence of both the bimolecular and free radical mechanisms Schmied and Fink cited the results of Ogg (4). In light of the fact that Ogg's mechanism is no longer accepted it seemed that these conclusions were questionable.

In addition, Flowers and Benson (9) demonstrated the following mechanism for the $\mathrm{CH}_{3} \mathrm{I}-\mathrm{HI}$ reaction:

$$
\mathrm{I}_{2}=2 \mathrm{I}, \quad(\mathrm{Keq}) \text {, }
$$




$$
\begin{aligned}
& \mathrm{I}+\mathrm{CH}_{3} \mathrm{I} \underset{2}{\stackrel{1}{\rightleftarrows}} \mathrm{CH}_{3}+\mathrm{I}_{2}, \\
& \mathrm{CH}_{3}+\mathrm{HI} \underset{4}{\stackrel{3}{\rightleftarrows}} \mathrm{CH}_{3} \mathrm{I}+\mathrm{H} .
\end{aligned}
$$

They found that step 1 had an activation energy of approximately $20 \mathrm{kcal}$. When combined with the dissociation energy for the production of one iodine atom it should yield an overall activation energy of approximately $38 \mathrm{kcal}$. for the isotopic exchange reaction. This value would be in agreement with the results of Clark et al. (6). However, the rate determining step is the formation of a free radical rather than an $S_{N} 2$ inversion of the methy1 jodide.

In summary, the isotopic exchange of iodine with methy 1 iodide poses the distinct problem of isolating the homogeneous exchange without the appreciable decomposition of methy 1 iodide. It was decided that the best technique available for assuring this condition was the shock tube method.

\section{B. The Shock Tube}

Although the physical possibility of shock waves was first realized in 1860 by Earnshaw (12), and the first safe and practical shock tube constructed by Vieille (13), in 1899, the development of the shock tube as an analytical tool in chemis- 
try was extremely slow. The interest in explosives and supersonic flow caused renewed activity in the field during World War II. Yet, the instrument was not used as a chemical tool. until 1953, when Carrington and Davidson (14) studied the dissociation of $\mathrm{N}_{2} \mathrm{O}_{4}$. Since that time the use of the shock tube in chemical kinetics has become widespread.

The advantages of the shock tube technique over many of the classical methods are numerous. Primarily, gases ahead of a shock wave are heated uniformly and almost instantaneously on passage through the shock front. Thus, reactants can be brought to reaction temperatures with virtually no heating time and the entire gas sample is brought to the same temperature. Secondly, because of the extremely short reaction times, virtually all surface reactions can be considered eliminated. Kevorkian, Heath, and Boudart (15) have demonstrated from simple kinetic theory that during the short duration of a reaction in a shock tube only a minute fraction of molecules in the gas could conceivably migrate to the surface. This feature is of obvious importance in the interpretation of data from the shock tube study of the exchange of iodine with methyl iodide. It is to be expected that any significant exchange which takes place at moderate temperatures could not be 
explained on the basis of a mechanism which suggests catalysis on the shock tube walls.

It would have been impossible to study an isotopic exchange reaction in a shock tube were it not for the advent of the single-pulse shock tube. First designed by Glick, Squire, and Hertzberg (16) and later refined by Lifshitz, Bauer, and Resler (17), this new technique assures that the gases under study, once heated to reaction temperature, are never reheated but are instead cooled back to the initial temperature. The extent of reaction can then be determined classically after removal of the reactants from the shock tube. Thus, reactions which cannot be followed in situ can be studied in this shock tube.

\section{Symbolism}

The range of symbols used in shock tube theory varies widely in the literature. To avoid confusion, a set of concise symbols is listed at this point. On the whole, this symbolism tends to conform with that of Glass and Hall (18).

1). $u$ Velocity of a gas in laboratory coordinates, i.e., with respect to the shock tube.

2). v Velocity of a gas with respect to a moving reference in the shock tube. 
3). $U_{I}, U_{R}$ Laboratory velocities of incident and reflected shocks, respectively.

4). $M_{I}$ Mach number of incident shock wave.

5). T. Temperature, in degrees Kelvin.

6). p Pressure.

7). $\rho$ Density.

8). R Universal gas constant.

9). $c_{p}, c_{v}$ Specific heats at constant pressure and volume, respectively.

10). $\gamma$ Ratio $c_{p} / c_{v}$.

11). $\alpha$ Ratio $\gamma+1 / \gamma-1$.

12). $\beta \quad$ Ratio $\gamma-1 / 2 \gamma$.

13). a speed of sound.

14). s Specific entropy.

15). e Specific internal energy.

16). h Specific enthalpy.

17). $\mathrm{H}^{\mathrm{O}}-\mathrm{H}_{\mathrm{O}}^{\mathrm{O}} / \mathrm{T}$ Standard molar enthalpy function.

18). M Molecular weight.

19). $\Gamma_{i j} \quad$ Ratio of density of gas $i$ to that of gas $j$.

20). $P_{i j} \quad$ Same as above, for pressures.

21). Tij Same as above, for temperatures.

22). $A_{i j}$ Same as above, for sound speeds.

23). $u_{i j}$ Ratio of laboratory velocity of gas $i$ to sound speed of gas $j$. 
24). $v_{i j \ldots} \ldots$

Ratio of relative velocity of gas $i$ to sound speed of gas $j$.

25). $x$

Mole fraction.

26). $\emptyset$

Degree of dissociation.

27). F

Fraction of exchange. 
II. . SHOCK TUBE THEORY: EXPERIMENTAL DEVELOPMENT
A. Fundamental Shock Tube Behavior

Before discussing any technical aspects of shock tube technology or theory, a brief nonmathematical description of shock tube behavior is presented here. The geometry of a shock tube is usually that of a long, straight, narrow cylinder. By using a straight shock tube the flow problem is reduced to one dimension, $\underline{\underline{i}}$.e., any thermodynamic or dynamical variable is a constant throughout any given plane perpendicular to the tube axis. Thus, processes in a straight shock tube can be described by the simple $x-t$ diagram of Figure 2 . The $x$-coordinate represents position in the shock tube while the $t$-coordinate measures the time from the initiation of the experiment. Prior to the experiment a diaphragm is placed at the point $\mathrm{A}$ which isolates the two sections of the shock tube. The reactants, diluted by an inert gas, are admitted into the longer end of the tube and referred to as gas 1 . The other section, called the driver section, is filled with inert gas at a significantly higher pressure. The inert driver gas is referred to as gas 4. After the diaphragm is ruptured a shock wave is formed which travels into the low pressure section. The path of the shock wave is denoted by the line AB. Gas 2 


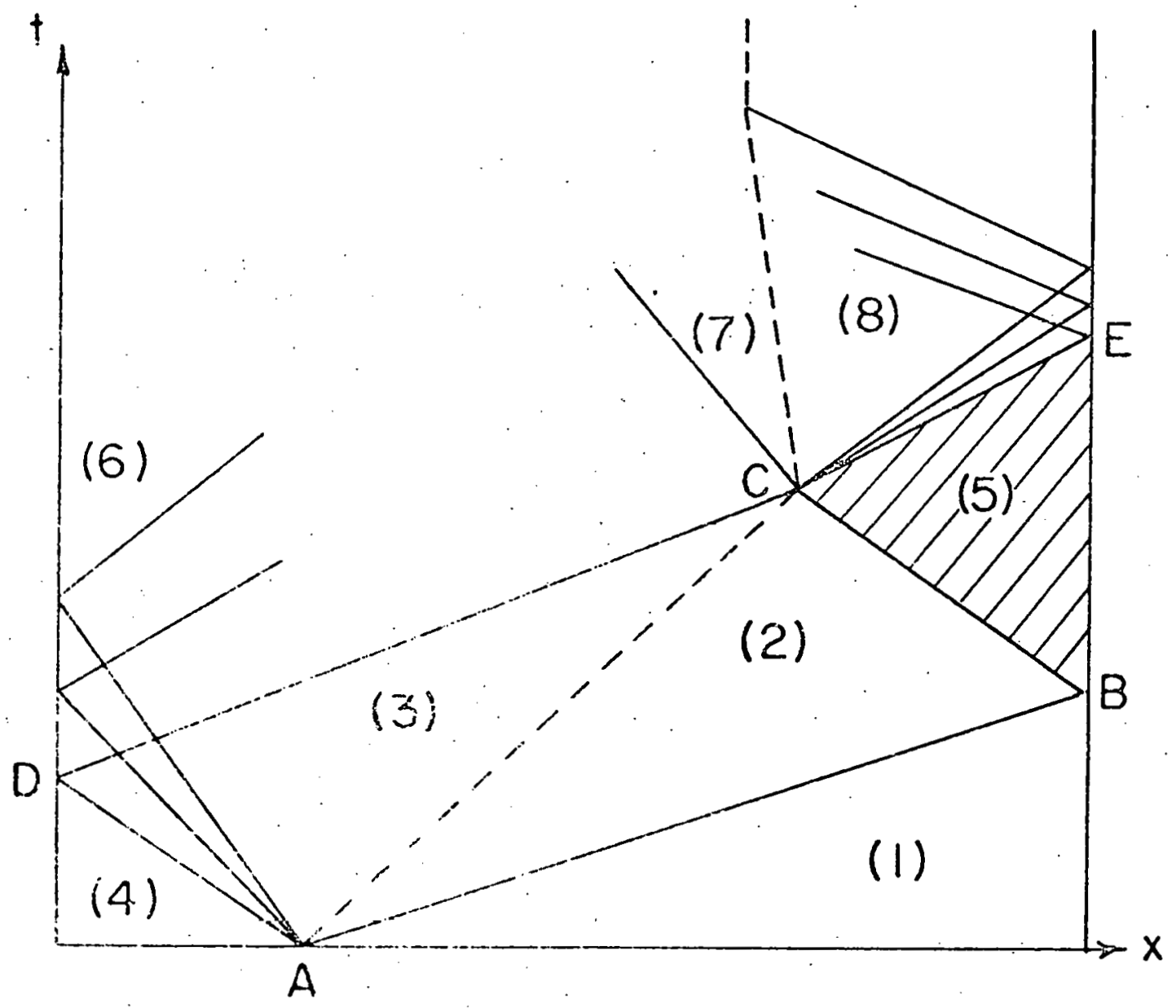

Figure 2. Phenomena in the single-pulse shock tube illustrated in $x-t$ coordinates 
consists of the reactants which have been heated and compressed by the shock wave and are travelling in the same direction as the shock. At the time the shock wave is formed an expansion wave is simultaneously generated into the driver gas. Gas 3 represents the inert driver which has been cooled and expanded by the expansion wave. Between gas 2 and gas 3 there exists a discontinuity, known as a contact surface, across which there is no mass flow. The contact surface traverses a path in $x-t$ space as shown by line AC. The pressure and gas velocity are continuous across the contact surface although the remaining thermodynamic variables are not.

In the chemical shock tube the reactants are not brought to reaction temperature by the incident shock wave. Instead, the final heating is done by the reflected shock wave, denoted by line BC. Normally, the temperature behind the incident shock wave is several hundred degrees lower than the temperature behind the reflected shock wave and thus the extent of reaction in gas 2 is negligible. The reaction is then quenched by an expansion wave generated from point C. Under special conditions, discussed in Section III-A, the interaction of a shock wave and a contact surface results in the formation of this expansion front, denoted by line $C E$. To make the cooling 
the most efficient the length of the driver section is adjusted such that the reflected far-end expansion wave coincides with the expansion wave formation at the point $\mathrm{C}$, resulting in their reinforcement. This results in a rapid cooling, determined in several cases by Lifshitz et al. $(17,19)$ as $10^{6} \mathrm{deg} . / \mathrm{sec}$, although it is by no means as rapid as the heating. All the significant reaction thus takes place in the slashed region 5 . Before removing the reactants from the shock tube it is necessary to insure against their being reheated by another reflection of the shock wave. This is discussed further in Section II-C. At this point the reactants are in a suitable state for removal and analysis.

\section{B. Shock Wave Generation}

The known methods of shock wave generation are numerous and depend on the type of experiment being studied and the temperatures or pressures desired. Rather than being given an iumense treatise, the reader is referred to the excellent reviews of Bradley (20) and Greene and Toennies (21).

The use of explosives to generate shock waves is both the oldest and most dangerous technique known. When studying the effects of very high pressures on liquids it is necessary to deliver an extremely strong shock to the liquid. Unlike their 
effect in gaseous systems, shock waves in liquids produce high pressure jumps with only moderate temperature elevation. For this purpose the explosive driver technique has been well developed by several workers $(22,23,24)$. For the temperatures required for chemical reactions it is not necessary to resort to such violent methods.

The study of chemical kinetics is normally carried out with the use of thin diaphragms. The diaphragms are ruptured either by puncturing with a needle or by building the pressure of the driver gas until the diaphragm bursts spontaneously. Aluminum or brass foils and plastic films are the most frequently used diaphragm materials.

Metal foils, with the employment of rigorous standardization techniques, can provide better reproducibility than the plastic films for the spontaneous bursting process. Metal diaphragms are usually scored so that they burst in a petal pattern and the petals flatten out against the side wall. Without scoring, these diaphragms might leave fragments extending into and interfering with the flow. Obviously, a standard scoring method must be used if reproducibility is desired. The bursting pressures of various scored and unscored metallic and plastic diaphragms have been tabulated by Bradley (20, p. 
115) and Greene and Toennies (21, p. 122).

Plastic films, though generally not available in as many thicknesses as the metallic foils, are preferable in chemical kinetics studies where extremely high temperatures are not necessary. Cellophane, known as a 'shatter'-type material, received early popularity in shock tube experiments and its properties were well outlined $(25,26)$. Upon bursting, cellophane shatters into many small fragments. Because the diaphragm effectively disappears, the shock wave is formed almost instantaneously. This material suffers from the fact that the shock tube requires extensive cleaning after each experiment. Mylar, on the other hand, is known as a 'tear'-type diaphragm. Upon bursting it tears and wraps itself along the shock tube wal1. Unfortunately, the slowness of the tearing process results in the formation of the shock front a significant distance from the diaphragm location.. This is compensated by having a long reactant section in the shock tube so that most of the gas sample is heated by a well formed shock wave. In view of the fact that the shock tube used in this study had extra shielding because of the radioactive gases used, a vigorous cleaning after each experiment was not practical and it was decided that Mylar film be used. To add flexibility, 
a plunger was used to burst the diaphragms at pressures slight1y below the spontaneous bursting pressure.

\section{Quenching Technique}

As mentioned previously, when a reaction cannot be followed in progress it is necessary to quench the reaction in the shock tube before removal of the reactants for analysis. Glick, Squire, and Hertzberg (16) were the first workers to develop this technique. They attached an evacuated tank, separated by a second diaphragm, onto the end of the driver section. This diaphragm would be at the point $\mathrm{x}=0$ in Figure 2. The diaphragm was ruptured when the far-end expansion wave reached it at point $D$, causing a reinforcement of the expansion wave denoted by line DC. The tank also served to attenuate the reflected shock wave from point $C$ by trappins it in the tank.

An improved shock tube was designed and tested by Klepeis (27). The cooling effect was caused predominantly by the interaction of the reflected shock wave and the contact surface to produce a rarefaction. In addition, a tank was directly connected to the shock tube, perpendicular to the tube axis. The tank, added on the downstream side of the diaphragm, effectively attenuated the reflected shock wave and prevented 
reheating of the reactants. Moreover, Klepeis determined that the incident shock wave and the reflected far-end expansion wave were only slightly affected by the presence of the tank. There are several advantages of this design over that of Glick et al. Primarily, the auxiliary apparatus needed to burst two diaphragms at a given time interval is quite formidable. Secondly, in the Klepeis design the dump tank is at the same pressure as the reactant section and this removes the necessity of accessory valves, diaphragms, and vacuum lines. Finally, the Klepeis tube gives a higher cooling rate than available in the other design. In view of the successful use of the simpler tube by many workers in the field, it was decided that a tube of similar design would be used for the exchange experiment. The design is illustrated in Figure 9 of Section IV-B.

\section{Measurement of Shock Parameters}

A full development of shock tube theory, outlined in Sections. III-A and III-B, yields a set of four equations in five unknowns: These five variables are the pressure and density nr temperature on both eides of the shock wave and the velocity of the gas with respect to the shock front on either side of it. A measurement of any one of these quanti- 
ties exactly determines the final state behind the shock wave. However, measurements of this type are difficult because reaction times in a shock tube are only of the order of a millisecond.

Piezo-electric transducers have been extensively used for direct pressure measurement. Transducers operate on the principle that the charge distribution on the faces of a piezoelectric crystal is dependent on the pressure on the crystal. These crystals are very sensitive to extremely rapid pressure changes and this property will be discussed shortly. However, while attempting to measure a constant pressure for any significant time the charge on the crystal faces decays and the resulting pressure measurement is very inaccurate.

Numerous workers have used the Mach-Zehnder interferometer to make direct density measurements. This technique is based on the principle that a change in density of a gas results in a. change in its refractive index and thus a change in the optical path length. Combining a reference beam with the beam through the gas sample it is possible to obtain interference fringes. The number of fringes will depend on the difference in phase of the two beams. Unfortunately, the interferometer is sensitive to small density changes only when the density of 
the gas sample is very large. In most chemical kinetics problems this condition does not exist.

In kinetics studies the variable which is most significant for data interpretation is, of course, the temperature. Efforts to directly measure temperatures behind shock waves have been attempted since the development of the sodium linereversal technique for the determination of flame temperatures $(28,29)$. Sodium-line radiation, when passed through a gas containing sodium vapor, causes the atoms to emit or absorb radiation depending on whether the temperature of the gas is higher or lower than that of the source. The intensity of the emission or absorption will depend on the magnitude of the temperature difference and the concentration of the sodium vapor in the gas. Since the sodium vapor concentration is difficult to estimate, it is necessary to carry out a series of identical shocks using various lamp temperatures until one is found at which the line intensity is not affected by the gas. This can be a terribly tedious operation.

It was mentioned earlier that measurement of the velocity of the gases on either side of the shock wave, with respect to the shock wave, would determine the final state of the system. It is shown in the next section that the shock wave 
velocity is simply related to the gas velocities. Thus, a measurement of the shock wave velocity is sufficient to completely determine the final state of the system. Piezoelectric transducers have proven to be very sensitive to the sharp pressure changes brought about by the passage of a shock through a gas. The placement of two or more transducers in a shock tube, set at calibrated distances apart, results in a very accurate determination of the shock wave velocity... The ample demonstration in the literature of the effectiveness of this technique $(16,17,19,30,31)$ resulted in its adoption in the shock tube designed for the iodine exchange.

It is necessary to make an additional remark at this point. Ideal shock tube theory leads to the result that a measurement of the incident or reflected shock wave velocity will determine the same final state behind the reflected shock. However, experimentally, many workers have found this condition unfulfilled $(32,33,34,35)$. In studies where reflected shock temperatures would be in the region $1500-3000^{\circ} \mathrm{K}$, the actual temperature was found to be $30-60^{\circ}$ lower than that calculated from ideal theory. This disagreement becomes especially severe where reactions involving large exchanges of heat occur. The reaction will generally lead to the reflected 
shock wave being accelerated. This problem can be avoided by using the incident shock as a basis for calculations, since no reaction is known to take place behind it.

\section{E. Measurement of Progress of Reaction}

Measurement of reactions in progress can be studied by most spectroscopic methods when applicable to a particular problem. The time-of-flight mass spectrometer, first applied to shock tube investigations by Bradley and Kistiakowsky (36), is particularly useful for the detection of unstable intermediates. For problems where the cost of a time-of-flight mass spectrometer is prohibitive and where there are no characteristic absorption or emission bands, standard laboratory techniques must be employed. These range from volumetric analysis to gas chromatography. For the exchange of iodine with methyl iodide, the ease of procurement of the $\gamma$-ray emitter $I^{131}$ and the availability of excellent counting equipment dictated the technique to be used. 
III... SHOCK TUBE THEORY: THEORETICAL DEVELOPMENT

A. Ideal Shock Tube Theory

The theory of shock tube operation has been known since the end of the last century. Unfortunately, few authors have succeeded in providing a concise mathematical description of all the phenomena that occur in the single-pulse shock tube. Partial descriptions are available in the texts by Bradley (20), Greene and Toennies (21), and Wright (37). The simplest and most complete work on the theory of shock tube processes is that by Glass and Hall (18). Their work is most highly recommended for the reader desiring an intimate familiarity with the subject. Basic fluid mechanics is outlined in many excellent texts $(38,39,40)$.

In studying chemical reactions in a shock tube it is standard procedure not to consider the effects of heat conduction or viscosity. Certainly, in the temperature and density regions of kinetics studies, their contribution would be negligible. In addition, it is assumed throughout that a11 the gases obey the ideal gas law. This approximation is valid so long as the pressures of the reactants are low, which is the condition that prevails in the shock tube. In this section two additional conditions are applied. The gases are consid- 
ered to undergo no reaction, ionization, or dissociation, and their specific heats are taken as independent of temperature. These restifictions are removed in the next section.

There are two basic laws necessary for the development of shock tube theory. The first, which is an expression of the conservation of mass, is known as the equation of continuity. In vector notation it is written as follows:

$$
\frac{\partial \rho}{\partial t}+\vec{\nabla} \cdot \vec{p}=0
$$

where $\vec{\nabla}$ is the gradient operator and $\vec{v}$ is the fluid velocity. The second law, the fluid mechanical equivalent of Newton's Second Law, is sometimes written:

$$
\rho \frac{d \vec{v}}{d t}=-\vec{\nabla} p
$$

This form is not convenient to use because it contains the total derivative operator, $d / d t$, rather than the local derivative operator, $\partial / \partial t$. However, one employs the chain rule ( 39 ; p. 56) to yield:

$$
\frac{d}{d t}=\frac{\partial}{\partial t}+\vec{v} \cdot \vec{\nabla}
$$

Substituting in Equation 2 yields the equation commonly referred to as Euler's equation:

$$
\frac{\partial \vec{v}}{\partial t}+(\vec{v} \cdot \vec{\nabla}) \bar{v}=-\frac{1}{\rho} \vec{\nabla} \mathrm{p} .
$$


Steady flow refers to the situation in which all the variables of the flow are constants at any given point in the flow. In this circumstance the local time derivatives of Equations 1 and 4 vanish.

To describe the change of state of a gas passing through a shock it is convenient to treat the shock front as a surface of discontinuity. In reality, the thickness of the shock front is only several mean free paths and the approximation is valid. Then, conditions of steady flow may be considered to exist on both sides of the shock front. The continuity equation then becomes:

$$
\vec{\nabla} \cdot \overrightarrow{p v}=0
$$

Since the flow in a shock tube is in one dimension only, one may write:

$$
\rho v=\text { constant }
$$

Thus, the rate at which mass enters the shock front is the same as the rate at which it emerges. Before discussing energy conservation it is necessary to recall two fundamental thermodynamic relations: one, the Maxwell equation,

$$
\mathrm{h}=\mathrm{e}+\mathrm{p} / \mathrm{p}
$$

the other, the enthalpy equation for isentroplc processes,

$$
\mathrm{dh}=\mathrm{dp} / \mathrm{p} .
$$

The energy density, abbreviated ED, consists of the kinetic 
energy and the total internal energy. Hence,

$$
E D=\frac{1}{2} \rho v^{2}+\rho e=\frac{1}{2} \rho v^{2}+\rho h-p,
$$

by Equation 7 . The local time change is then written as:

$$
\frac{\partial}{\partial t}(E D)=\left(h+\frac{1}{2} v^{2}\right) \frac{\partial \rho}{\partial t}+\rho \vec{v} \cdot \frac{\partial \vec{v}}{\partial t}+\rho \frac{\partial h}{\partial t}-\frac{\partial p}{\partial t} .
$$

The last two terms vanish by virtue of Equation 8. If one now substitutes Equations 1 and 4 into the last equation, then the local time rate of change of energy density becomes:

$$
\frac{\partial}{\partial t}(E D)=-\left(h+\frac{1}{2} v^{2}\right) \vec{\nabla} \cdot p \vec{v}-\vec{v} \cdot \vec{\nabla} p-p \vec{v} \cdot\left(\frac{\vec{v}}{\nabla} \cdot \vec{\nabla}\right) \vec{v} .
$$

From vector analysis one draws on the following identity (39, p. 73):

$$
(\vec{v} \cdot \vec{\nabla}) v=\frac{1}{2} \vec{\nabla} v^{2}-\vec{v} x(\vec{\nabla} \times \vec{v}) .
$$

Using this relation, and substituting Equation 8 again, one obtains :

$$
\begin{aligned}
\frac{\partial}{\partial t}(E D) & =-\left(h+\frac{1}{2} v^{2}\right) \vec{\nabla} \cdot \rho \vec{v}-\rho \vec{v} \cdot \vec{\nabla} h-\rho \vec{v} \cdot \frac{1}{2} \vec{\nabla} v^{2} \\
& =-\vec{\nabla} \cdot \rho \vec{v}\left(h+\frac{1}{2} v^{2}\right) .
\end{aligned}
$$

Consequently, the change in energy in a given volume may be written as follows:

$$
\begin{aligned}
\frac{\partial}{\partial t} \int\left(\frac{1}{2} \rho v^{2}+\rho e\right) d V & =-\int \vec{\nabla} \cdot \rho \vec{v}\left(h+\frac{1}{2} v^{2}\right) d V \\
& =-\oint \rho \vec{v}\left(h+\frac{1}{2} v^{2}\right) \cdot d \vec{S},
\end{aligned}
$$


where the last relation is the result of the application of Gauss' divergence theorem. The right hand side of Equation 14 signifies that the rate at which energy crosses the volume boundary is given by the vector,

$$
\vec{p} \vec{v}\left(h+\frac{1}{2} v^{2}\right) \text {. }
$$

Since energy must be conserved in a shock system, this vector must be the same on both sides of the shock front. Reducing the equation to one dimension and making note of Equation 6 , one obtains:

$$
\mathrm{h}+\frac{1}{2} \mathrm{v}^{2}=\text { constant, }
$$

across a shock wave. Momentum flux is treated in the same manner, by finding the rate of change of the momentum density in a fixed volume. This may be written as:

$$
\begin{aligned}
\frac{\partial}{\partial t}(\overrightarrow{p v}) & =\vec{v} \frac{\partial \rho}{\partial t}+\rho \frac{\partial \vec{v}}{\partial t} \\
& =-\vec{v}(\vec{\nabla} \cdot \vec{\rho} \vec{v})-\rho(\vec{v} \cdot \vec{\nabla}) \vec{v}-\vec{\nabla} p,
\end{aligned}
$$

by virtue of the continuity equation and Euler's equation.

The first two terms are equivalent to the dyadic expression (39, p. 69),

$$
-\vec{\nabla} \cdot(\overrightarrow{p v v}) \text {. }
$$

Now, taking the integral over all the fluid, one writes:

$$
\frac{\partial}{\partial t} \int \rho \vec{v} d v=-\int \vec{\nabla} p d v-\int \vec{\nabla} \cdot(\vec{\rho} \vec{v}) d v
$$


The divergence theorem reduces Equation 17 to:

$$
\frac{\partial}{\partial t} \int \partial \vec{v} d V=-\oint p d \vec{S}-\oint \rho \vec{v} \vec{v} \cdot d \vec{S}
$$

Thus, the rate at which momentum crosses the surface is given by a tensor. However, the shock tube is a one dimensional structure and the conservation of momentum is simply written:

$$
p+\rho v^{2}=\text { constant }
$$

Equations 6,15 , and 19, together with an equation of state and an enthalpy function are the five basic equations of shock tube theory. All that is required for a complete description of the state behind a shock wave is a single measurement, as discussed earlier. However, these equations do not provide any insight into the functional dependence of the thermodynamic and mechanical parameters upon. one another. By proper algebraic rearrangements of these relations one can perceive the range of conditions available behind shock waves of various strengths.

It is convenient to discuss gaseous flow in a shock tube in terms of several different coordinate systems. All the coordinate systems used in the discussion are illustrated in Figure 3. The subscript convention is consistent with that of Figure 2. Instead of using vector notation throughout the derivation, it is to be understood that a velocity is positive 

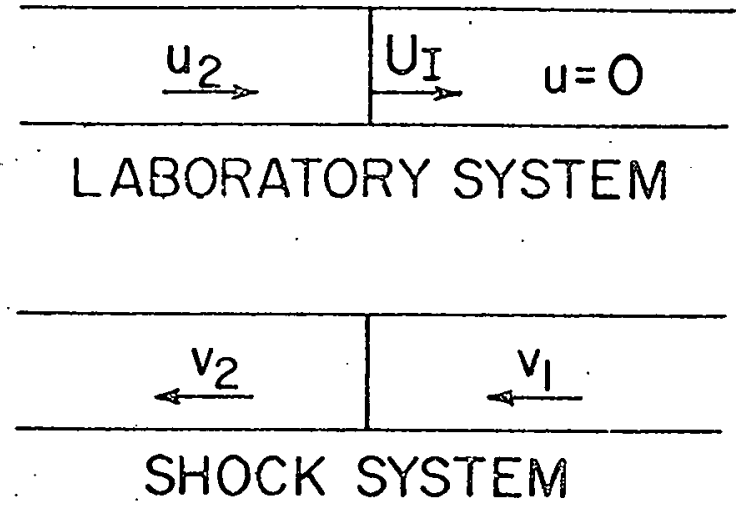

Figure 3a. Incident shock coordinate systems

\begin{tabular}{l|c|c}
\hline$\stackrel{u_{2}}{\longrightarrow}$ & $U_{R}$ & $u=0$ \\
\hline LABORATORY SYSTEM
\end{tabular}

\begin{tabular}{ll|l}
$V=0$ & $U_{R_{2}+U_{2}}$ & $v_{5}$ \\
\hline
\end{tabular}

RELATIVE SYSTEM

\begin{tabular}{c|c}
\hline$U_{R^{+}+U_{2}}$ & $\stackrel{U_{R}}{\longrightarrow}$ \\
\hline SHOCK SYSTEM
\end{tabular}

Figure 3b. Reflected shock coordinate systems 
whenever it is in the same direction that it has been assigned in Figure 3. This simplifies the notation because the directions assigned to the velocity vectors are in anticipation of the results. Consequently, the values of the velocities are consistently positive.

The conservation equations across the incident shock are rewritten as follows:

$$
\begin{aligned}
& \rho_{1} v_{1}=\rho_{2} v_{2}, \\
& h_{1}+\frac{1}{2} v_{1}{ }^{2}=h_{2}+\frac{1}{2} v_{2}{ }^{2},
\end{aligned}
$$

and

$$
\mathrm{p}_{1}+\mathrm{o}_{1} \mathrm{v}_{1}^{2}=\mathrm{p}_{2}+\mathrm{p}_{2} \mathrm{v}_{2}^{2} \text {. }
$$

In addition it is required that the gases be perfect and polytropic:

$$
\begin{aligned}
& \mathrm{p}={ }_{\mathrm{p} R T} \mathrm{M}, \\
& \mathrm{h}=\mathrm{c}_{\mathrm{p}} \mathrm{T}(+ \text { constant }),
\end{aligned}
$$

where the constant is taken as zero and $c_{p}$ is independent of temperature. Furthermore, one makes use of the following definition of the sound speed in a gas:

$$
==\left(\gamma_{\mathrm{p}} / \mathrm{p}\right)^{\frac{1}{2}}=\left(\gamma_{\mathrm{RT}} / \mathrm{M}\right)^{\frac{1}{2}} \text {. }
$$

The substitution of Equation 20 in Equation 22 yields:

$$
\left(f_{1} v_{1}\right)^{2}=\left(p_{2} v_{2}\right)^{2}=\frac{p_{1}-p_{2}}{1 / p_{2}-1 / \rho_{1}}
$$


Now, by rearranging Equation 21 one finds:

$$
h_{1}-h_{2}=\frac{1}{2}\left(v_{2}^{2}-v_{1}^{2}\right)=\frac{1}{2}\left(p_{1}-p_{2}\right)\left(\frac{1}{\rho_{2}}+\frac{1}{\rho_{1}}\right) .
$$

A1so, from Equations 23, 24, and 25 one may write:

$$
\begin{aligned}
h_{1}-h_{2}=c_{p}\left(T_{1}-T_{2}\right) & =\frac{R}{M}\left(\frac{c_{p}}{c_{p}-c_{v}}\right)\left(\frac{p_{1}}{\rho_{1} R}-\frac{p_{2} M}{\rho_{2} R}\right) \\
& =\frac{\gamma}{\gamma-1}\left(\frac{p_{1}}{\rho_{1}}-\frac{p_{2}}{\rho_{2}}\right),
\end{aligned}
$$

where use was made of the identity $c_{p}-c_{v}=R / M$. Also, for simplicity, the subscripts which should appear on the variable $\gamma$, and therefore on $\alpha$ and $\beta$, will not be included with the explicit understanding that the specific heats are independent of temperature. Equating the last two expressions, and performing the necessary algebra, one finds:

$$
\Gamma_{21}=\frac{1+\alpha P_{21}}{\alpha+P_{21}}
$$

Rearrangement of this expression yields the following result:

$$
P_{21}=\frac{\alpha \Gamma_{21}-1}{\alpha-\Gamma_{21}}
$$

Finally, using the ideal gas law, one derives these multiple identities:

$$
\mathrm{T}_{21}=\frac{\mathrm{P}_{21}}{\Gamma_{21}}=\stackrel{2}{\mathrm{~A}_{21}}=\mathrm{P}_{21} \frac{\alpha+\mathrm{P}_{21}}{1+\alpha \mathrm{P}_{21}} .
$$


Thus, the temperature jump behind a shock wave increases indefinitely with increasing $\mathrm{P}_{21}$. However, an analysis of the initial pressure ratio across the diaphragm, $\mathrm{P}_{41}$, and its relationship to $\mathrm{P}_{21}$ would demonstrate that for a given system $\mathrm{P}_{21}$ has a finite limit even for infinite $\mathrm{P}_{41}$. As a result, $\mathrm{T}_{21}$ also has a finite limit which is dependent on the nature of the gases on both sides of the diaphragm. For large $\mathrm{P}_{21}, \Gamma_{21}$ approaches an upper limit of $\alpha$. In Figure 4 plots of $\mathrm{T}_{21}$ and $\Gamma_{21}$ are given as functions of $\mathrm{P}_{21}$ for a polytropic gas. In passing, it is interesting to note that the entropy change across the shock front is given by:

$$
s_{2}-s_{1}=c_{v} \ln \left(\frac{P_{21}}{\Gamma_{21} \gamma}\right)=c_{v} \ln \left[P_{21}\left(\frac{\alpha+P_{21}}{1+\alpha P_{21}}\right)^{\gamma}\right] .
$$

Since the velocity of the shock wave is measured in a real system, not the pressure, it is instructive to change the functional forms obtained above. From Equation 26 , the gas velocity ahead of the shock may be written:

$$
{ }_{1}^{2}{ }^{2}=\frac{1}{\rho_{1}^{2}}\left(\frac{p_{1}-p_{2}}{1 / \rho_{2}-1 / \rho_{1}}\right)=\frac{p_{1}}{\rho_{1}}\left(\frac{1-P_{21}}{1 / \Gamma_{21}-I}\right) .
$$

Substituting Equations 25 and 29 one obtains:

$$
v_{1}^{2}=\frac{a_{1}^{2}}{\gamma}\left(\frac{1+\alpha P_{21}}{\alpha-1}\right)
$$

The expressions $\alpha$ and $\beta$ are simply related by: 


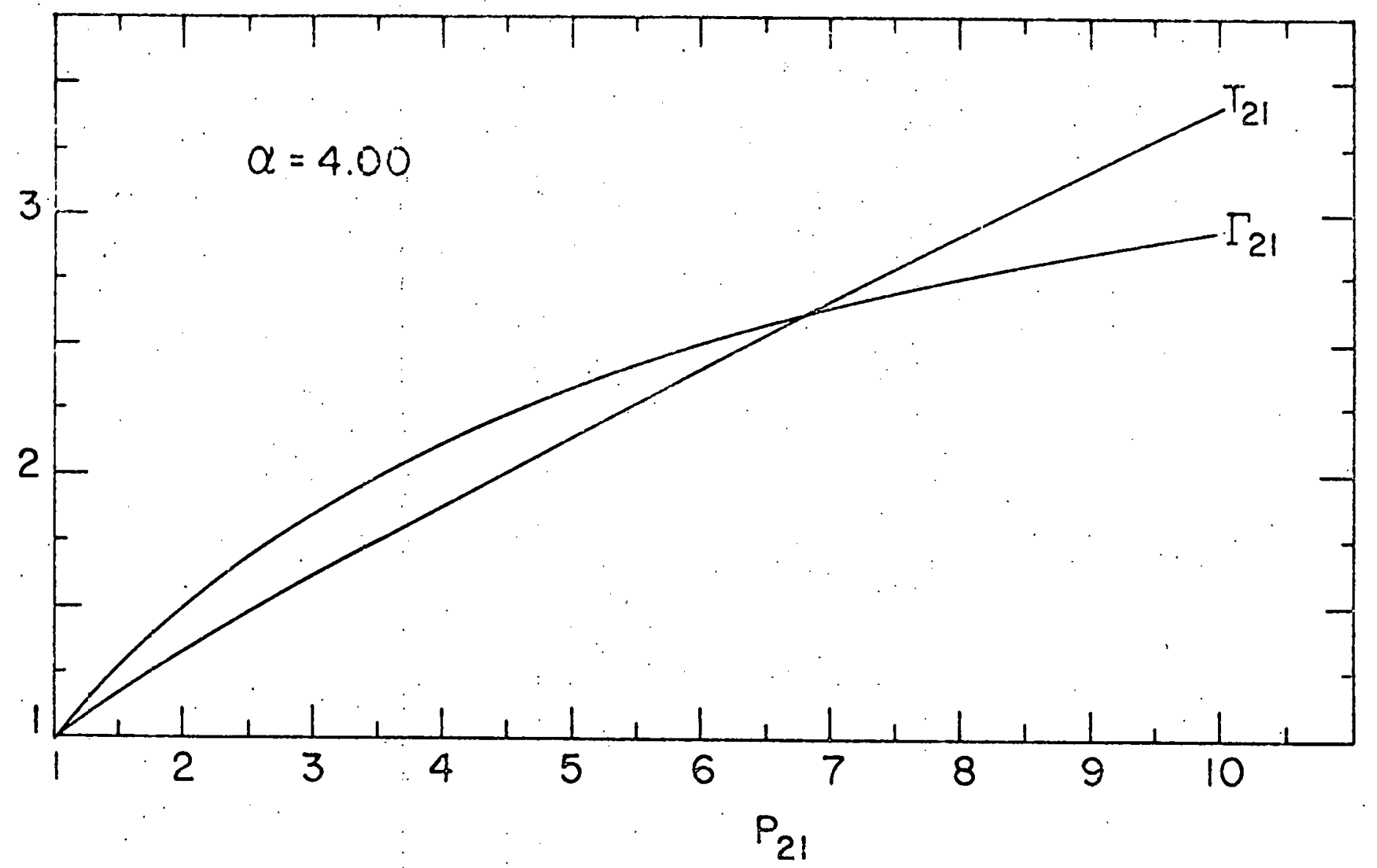

Figure 4. Variation of incident shock temperature and density ratios as a function of the pressure ratio 


$$
\alpha+1=1 / \beta \text { and } \alpha-1=1 / y \beta \text {. }
$$

Thus, Equation 34 may be simplified to:

$$
\mathrm{V}_{11}^{2}=\frac{1+\alpha \mathrm{P}_{21}}{\gamma(\alpha-1)}=\frac{1+\alpha \mathrm{P}_{21}}{1+\alpha}
$$

The last equation illustrates the simple fact that a shock wave always travels faster than the sound speed in the gas ahead of it. Since $v_{1}$ and $U_{I}$ are identical, the Mach number, $\mathrm{M}_{I}$, is identical with $\mathrm{V}_{11}$. This leads to the important result:

$$
\mathrm{P}_{21}=\frac{1+\alpha}{\alpha} \mathrm{M}_{\mathrm{I}}^{2}-\frac{1}{\alpha}
$$

Using Equation 26 once more one finds:

$$
\mathrm{v}_{21}{ }^{2}=\frac{\left(\alpha+\mathrm{P}_{21}\right)^{2}}{(1+\alpha)\left(1+\alpha \mathrm{P}_{21}\right)}
$$

One converts this result to the laboratory system to obtain:

$$
\mathrm{U}_{21}=\mathrm{V}_{21}-\mathrm{v}_{11}=\frac{(\alpha-1)\left(\mathrm{P}_{21}-1\right)}{\left[(1+\alpha)\left(1+\alpha \mathrm{P}_{21}\right)\right]^{\frac{1}{2}}},
$$

after much algebra. Obvious $1 y$, this term is positive and it indicates that the gas behind the shock wave is moving in the same direction as the shock wave. A comparison of Equation 39 with Equation 36 shows that the gas is not travelling as fast as the shock. Using Equation 37, Equations 29 and 31 can be rewritten in the following forms:

$$
\Gamma_{21}=\frac{\alpha \mathrm{M}_{I}^{2}}{\alpha-1+\mathrm{M}_{I}^{2}}
$$




$$
\mathrm{T}_{21}=\frac{\left[(1+\alpha) \mathrm{M}_{\mathrm{I}}^{2}-1\right]\left[\alpha-1+\mathrm{M}_{\mathrm{I}}^{2}\right]}{\alpha^{2} \mathrm{M}_{\mathrm{I}}{ }^{2}}
$$

To contrast with the temperatures and densities of Figure 4, a plot of the incident shock Mach number over a range of shock pressures is given in Figure 5, as calculated from Equation 36.

To ascertain the state behind a reflected shock wave one must have a boundary condition for the end wall reflection. Simply stated, the gas behind the reflected shock wave must be at rest since the gas initially at the end wall was at rest. This condition has been included in the reflected shock coordinate systems of Figure 3. By analogy with Equation 39, one may write the following for the flow velocity behind the reflected shock wave:

$$
v_{52}=\frac{(\alpha-1)\left(P_{52}-1\right)}{\left[(1+\alpha)\left(1+\alpha P_{52}\right)\right]^{\frac{1}{2}}} \text {. }
$$

Since $v_{5}$ and $u_{2}$ are identical, division of Equation 39 by Equation 42 yields:

$$
A_{21}=\frac{U_{21}}{V_{52}}=\left[\frac{P_{21}-1}{P_{52}-1}\right]\left[\frac{1+\alpha P_{52}}{1+\alpha P_{21}}\right]^{\frac{1}{2}} .
$$

From the definition of $A_{21}$ by Equatica 31, one obtains the following identity:

$$
P_{21} \frac{1}{2}\left[\frac{\alpha+P_{21}}{1+\alpha P_{21}}\right]^{\frac{1}{2}}=\left[\frac{P_{21}-1}{P_{52}-1}\right]\left[\frac{1+\alpha P_{52}}{1+\alpha P_{21}}\right]^{\frac{1}{2}} \text {. }
$$




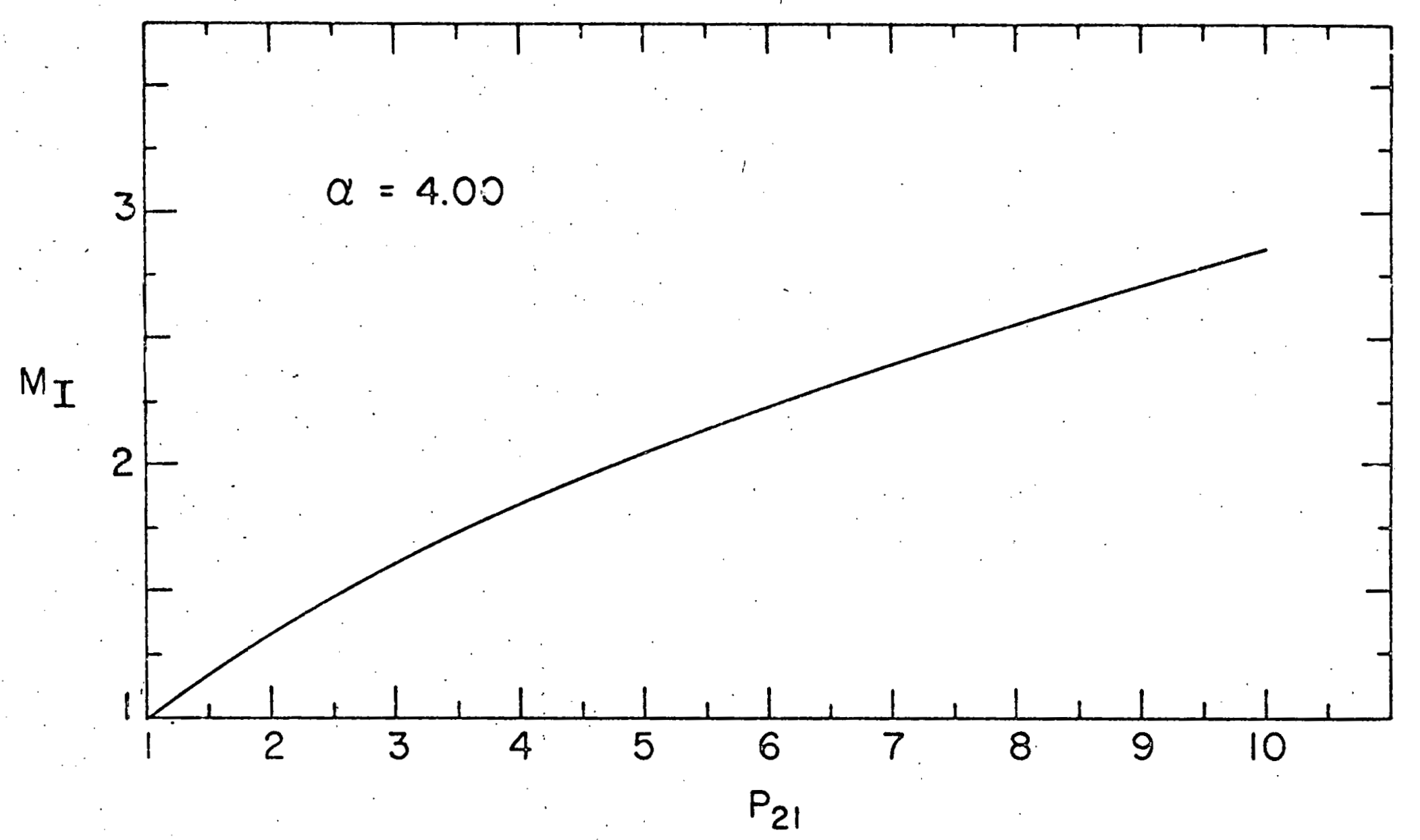

a

Figure 5. Variation of the Mach number of an incident shock wave as a function of the pressure ratio 
Solving this quadratic results in the determination of two roots for $\mathrm{P}_{52}$, one of which is rejected for being less than unity. The other root is determined to be the following:

$$
\mathrm{P}_{52}=\frac{(\alpha+2) \mathrm{P}_{21}-1}{\alpha+\mathrm{P}_{21}}
$$

Similarly, the density ratio associated with the reflected shock wave has the same functional form as Equation 29 and may be written:

$$
\Gamma_{52}=\frac{1+\alpha \mathrm{P}_{52}}{\alpha+\mathrm{P}_{52}} .
$$

Substitution of Equation 45, and rearrangement, yie1ds the following:

$$
\Gamma_{52}=\frac{(\alpha+1) P_{21}}{\alpha-1+2 P_{21}}
$$

Using the ideal gas law one obtains:

$$
T_{52}=\frac{P_{52}}{\Gamma_{52}}=\left[\frac{(\alpha+2) P_{21}-1}{\alpha+P_{21}}\right]\left[\frac{\alpha-1+2 P_{21}}{(\alpha+1) P_{21}}\right] \text {. }
$$

By m11tiplying $P_{52}, \Gamma_{52}$, and $T_{52}$ by $P_{21}, \Gamma_{21}$, and $T_{21}$, respectively, one obtains the following expressions:

$$
\begin{aligned}
& P_{51}=\frac{(\alpha+2) P_{21}-P_{21}}{\alpha+P_{21}}, \\
& \Gamma_{51}=\left[\frac{1+\alpha P_{21}}{\alpha+P_{21}}\right]\left[\frac{(\alpha+1) P_{21}}{\alpha-1+2 P_{21}}\right],
\end{aligned}
$$

and 


$$
\ldots-T_{51}=\left[\frac{(\alpha+2) P_{21}^{2}-P_{21}}{1+\alpha P_{21}}\right]\left[\frac{\alpha-1+2 P_{21}}{(\alpha+1) P_{21}}\right] \text {. }
$$

Equations 50 and 51 are plotted, for an ideal gas, in Figure 6, while Equation 49 is demonstrated in Figure 7. For purposes of calculation it is again much more convenient to write $P_{51}, \quad \Gamma_{51}$, and $T_{51}$ as direct.functions of the incident shock Mach number. By direct substitution of Equation 37 into Equations 49,50 , and 51 , one finds

$$
\begin{aligned}
& P_{51}=\left[\frac{1+\alpha}{\alpha} \mathrm{M}_{I}^{2}-\frac{1}{\alpha}\right]\left[\frac{(\alpha+2) \mathrm{M}_{I}^{2}-2}{\alpha-1+\mathrm{M}_{I}^{2}}\right], \\
& \Gamma_{51}=\left[\frac{\alpha \mathrm{M}_{I}^{2}}{\alpha-1+\mathrm{M}_{I}^{2}}\right]\left[\frac{(\alpha+1) \mathrm{M}_{I}^{2}-1}{\alpha-2+2 \mathrm{M}_{I}^{2}}\right],
\end{aligned}
$$

and

$$
\mathrm{T}_{51}=\frac{\left[\alpha-2+2 \mathrm{MI}^{2}\right]\left[(\alpha+2) \mathrm{MI}^{2}-2\right]}{\alpha^{2} \mathrm{M}_{I}^{2}},
$$

respectively.

In many instances it is more convenient to make a measurement of only the reflected shock wave velocity. By analogy with Equation 36, a study of the reflected shock in the rela-. tive coordinate systen yields:

$$
\frac{\mathrm{U}_{\mathrm{R}}+\mathrm{u}_{2}}{\mathrm{a}_{2}}=\left[\frac{1+\alpha \mathrm{P}_{52}}{1+\alpha}\right]^{\frac{1}{2}}
$$




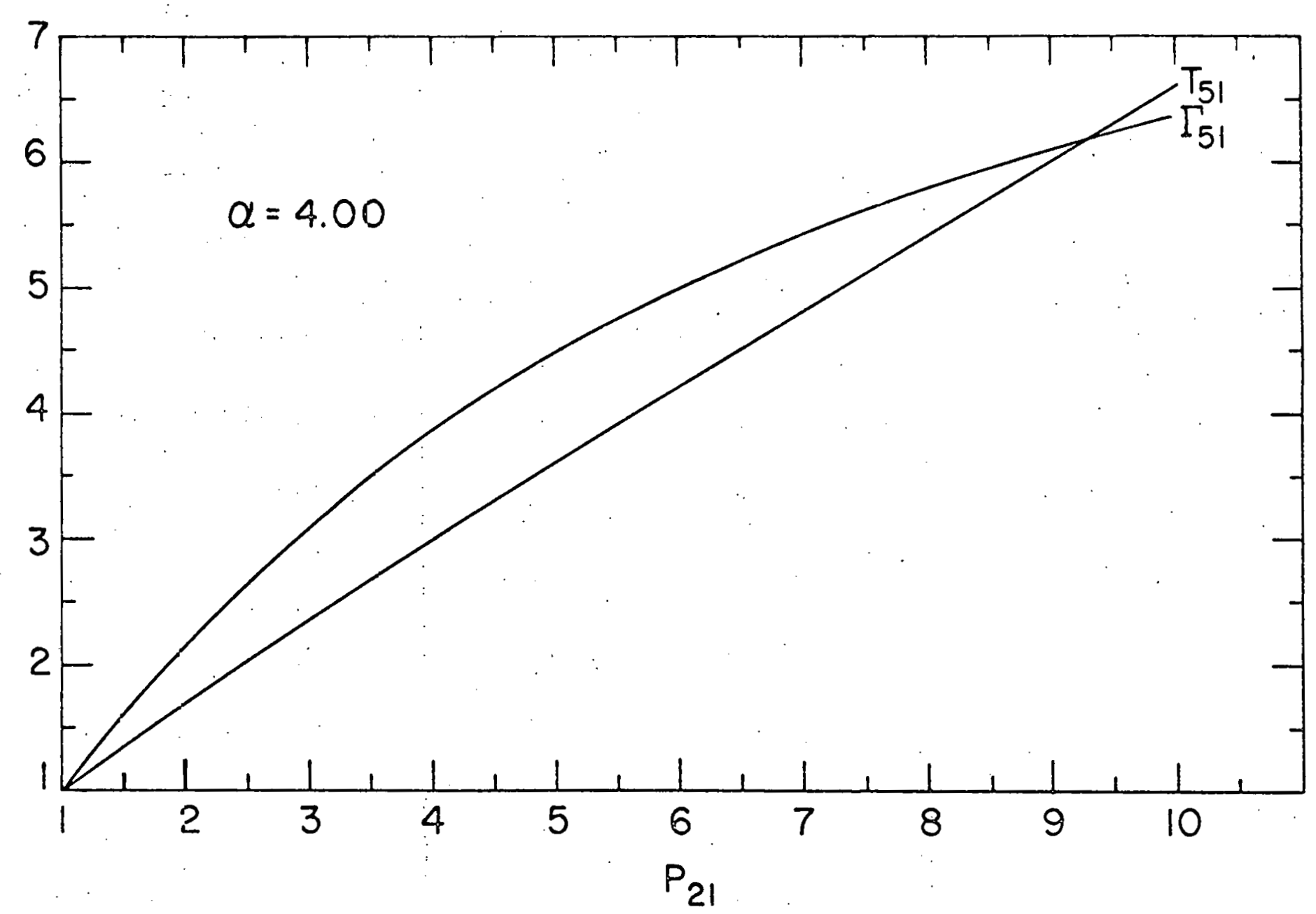

Figure 6. Variation of reflected shock temperature and density ratios as a function of the incident shock pressure ratio 


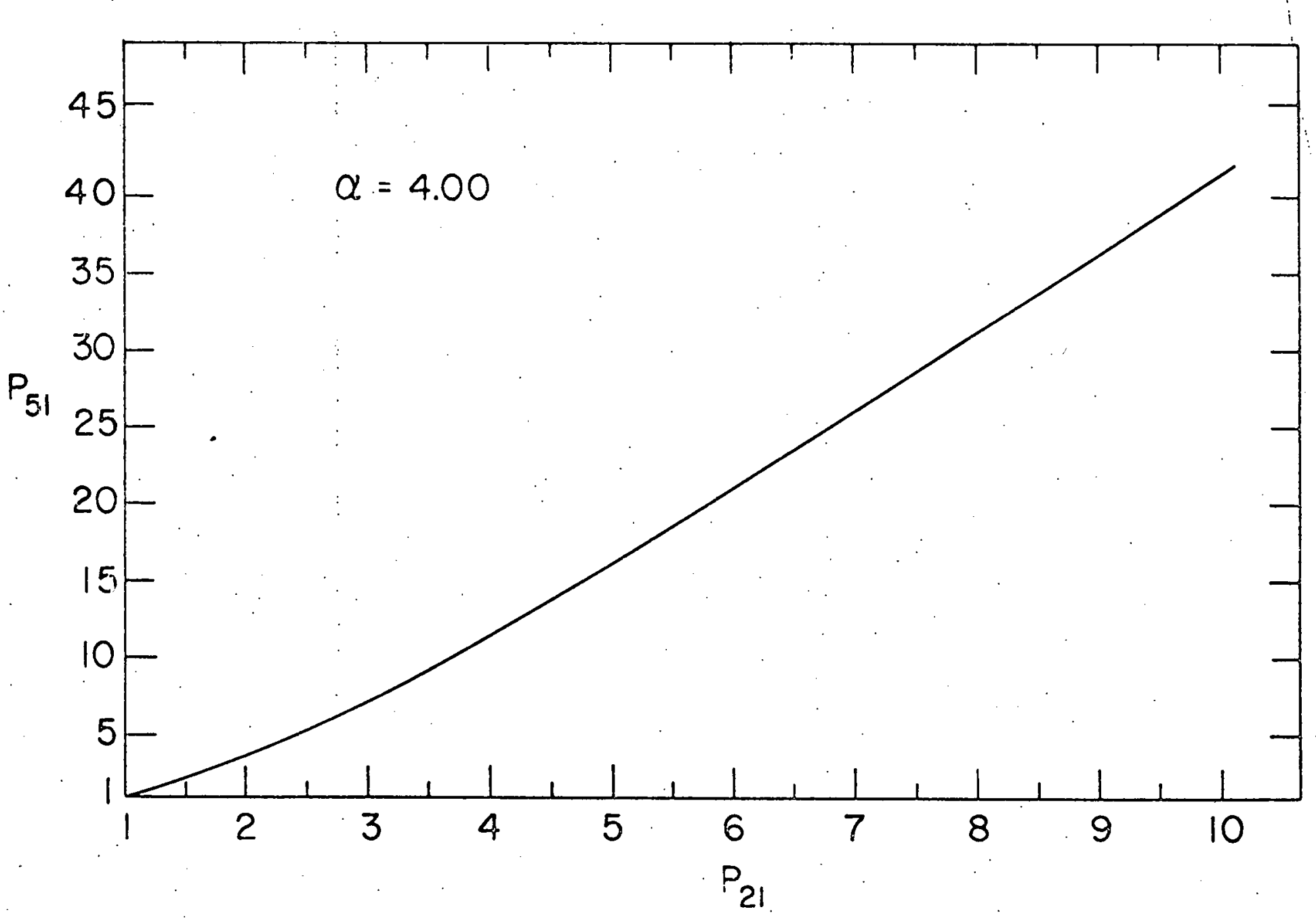

Figure 7. Variation of the reflected shock pressure ratio as a function of the incident shock pressure ratio 
By a simple rearrangement, the last equation is reduced to the form:

$$
\frac{U_{R}}{a_{1}}=A_{21}\left[\frac{1+\alpha P_{52}}{1+\alpha}\right]^{\frac{1}{2}}-\frac{u_{2}}{a_{1}}
$$

The proper substitution of Equations 31, 39, and 45 converts Equation 56 into the following form:

$$
\frac{U_{R}}{a_{1}}=\frac{2 P_{21}+\alpha-1}{\left[(1+\alpha)\left(1+\alpha P_{21}\right)\right]^{\frac{1}{2}}}
$$

A1so, further substitution of Equation 37 yields:

$$
\frac{U_{R}}{a_{1}}=\frac{2 M_{I}^{2}+\alpha-2}{{ }^{Q M_{I}}} .
$$

Equation 58 illustrates the simple connection that exists between the incident and reflected shocks in ideal systems. Note that for an ideal monatomic gas, for which $\alpha=4$, the reflected shock velocity is always lower than the incident shock velocity. This is true in laboratory coordinates, but one should keep in mind that the reflected shock wave is travelling into a moving gas. Its relative velocity is actually larger than that of the incident shock.

There is one additional phenomenon in the shock tube that deserves elucidation. The quenching mechanism for a kinetics experiment is initiated by the interaction of the reflected shock wave with the contact surface, as illustrated in Figure 
2. Since the generation of an expansion wave is not always the result of such an interaction, it is necessary to determine what special conditions will assure that one obtains a cooling wave. The coordinate systems of Figure 8 illustrate the conditions existing prior to, and following, the interaction at the contact surface. For the derivation that follows the reflected far-end expansion wave is ignored, and the contact surface is taken at rest in the initial system. This shift in the coordinate system leaves the result completely general. The conditions across and through a rarefaction wave can be derived from the method of characteristics. The method is outlined in many texts $(18,20,37)$ and is briefly introduced in the Appendix. Across the reflected rarefaction wave the velocities are related by the following equation:

$$
v_{8}-v_{5}=\frac{a_{5}}{\gamma_{5} \beta_{5}}\left[1-P_{85}^{\beta_{5}}\right]
$$

The velocities behind the initial and transmitted shock waves, by analogy with Equation 39, are given by the following relations:

$$
\begin{aligned}
& v_{5}=\frac{a_{2}\left(\alpha_{1}-1\right)\left(P_{52}-1\right)}{\left[\left(1+\alpha_{1}\right)\left(1+\alpha_{1} P_{52}\right)\right]^{\frac{1}{2}}}, \\
& v_{7}=\frac{a_{3}\left(\alpha_{4}-1\right)\left(P_{73}-1\right)}{\left[\left(1+\alpha_{4}\right)\left(1+\alpha_{4} P_{73}\right)\right]^{\frac{1}{2}}} .
\end{aligned}
$$




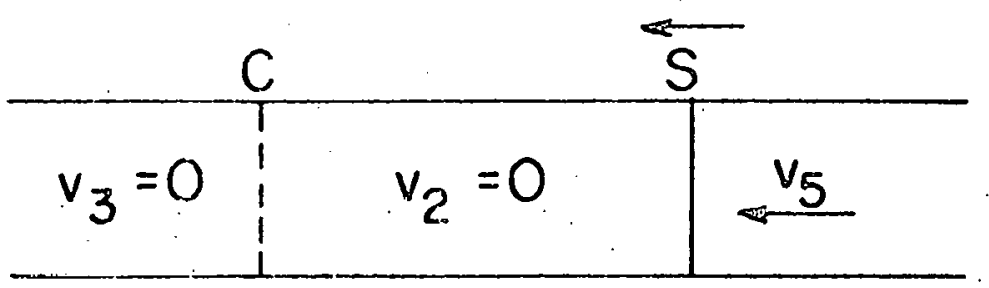

INITIALSTATE

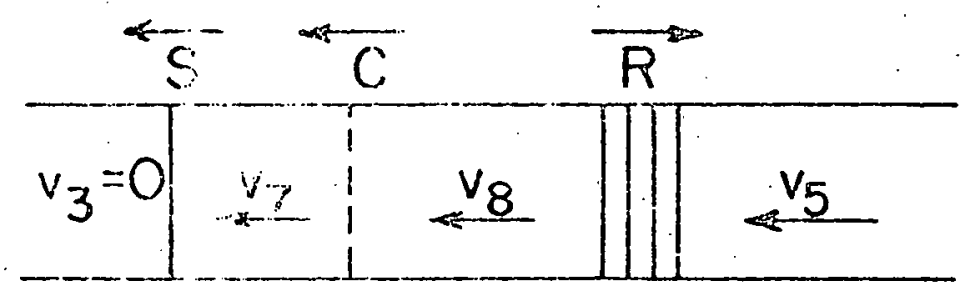

FINAL STATE

Figure 8. Shock tube states before and after the refraction of a shock wave by a contact. surface 
Recall that the subscript 4 refers to the driver gas, which is also considered to be polytropic. Across the contact surface, before and after the interaction, the following boundary conditions apply:

$$
\mathrm{p}_{2}=\mathrm{p}_{3}, \mathrm{p}_{7}=\mathrm{p}_{8} \text {, and } \mathrm{v}_{7}=\mathrm{v}_{8} \text {. }
$$

Thus, Equations 59, 60, and 61 may be equated to yield:

$$
\frac{a_{5}}{\gamma_{5} \beta_{5}}\left[1-P_{85}^{\beta_{5}}\right]=\frac{a_{3}\left(\alpha_{4}-1\right)\left(P_{82}-1\right)}{\left[\left(1+\alpha_{4}\right)\left(i+\alpha_{4} P_{82}\right)\right]^{\frac{1}{2}}}-\frac{a_{2}\left(\alpha_{1}-1\right)\left(P_{52}-1\right)}{\left[\left(i+\alpha_{1}\right)\left(1+\alpha_{1} P_{52}\right)\right]^{\frac{1}{2}}} .
$$

Rearrangement of this equation yields:

$$
P_{75}{ }^{B_{5}}-1+\frac{\gamma_{5}{ }_{5} A_{32} A_{25}\left(\alpha_{4}-1\right)\left(P_{82}-1\right)}{\left[\left(1+\alpha_{4}\right)\left(1+\alpha_{4} P_{82}\right)\right]^{\frac{1}{2}}}-\frac{\gamma_{5}{ }_{5} A_{25}\left(\alpha_{1}-1\right)\left(P_{52}-1\right)}{\left[\left(1+\alpha_{1}\right)\left(1+\alpha_{1} P_{52}\right)\right]^{\frac{1}{2}}} .
$$

One now substitutes for $A_{25}$, using the functional form of Equation 31, to derive the following equation for $P_{75}$ :

$$
\begin{aligned}
P_{75}{ }^{\beta_{5}} & -1+\frac{\gamma_{5} \beta_{5} A_{32}\left(1+\alpha_{1} P_{52}\right)^{\frac{1}{2}}\left(\alpha_{4}-1\right)\left(P_{82}-1\right)}{\left[P_{52}\left(\alpha_{1}+P_{52}\right)\left(1+\alpha_{4}\right)\left(1+\alpha_{4} P_{82}\right)\right]^{\frac{1}{2}}} \\
& -\frac{\gamma_{5} \beta_{5}\left(\alpha_{1}-1\right)\left(P_{52}-1\right)}{\left[\left(1+\alpha_{1}\right)\left(1+\alpha_{1} P_{52}\right)\right]^{\frac{1}{2}}}=0 .
\end{aligned}
$$

The condition that an expansion wave be reflected is that $P_{75}$ <1. Thus, the third term in Equation 64 must be larger than the fourth. This condition, after the appropriate cancellations and rearrangement of Equation 64, yields: 


$$
A_{32}>\left[\frac{\alpha_{1}-1}{\alpha_{4}-1}\right]\left[\frac{\alpha_{4}+1}{\alpha_{1}+1}\right]^{\frac{1}{2}}\left[\frac{1+\alpha_{4} P_{52}}{1+\alpha_{1} P_{52}}\right]^{\frac{1}{2}}
$$

Usually, the driver gas in a shock tube is a monatomic gas such as helium, so the last two terms in the product above are close to unity. By approximation, the condition in Equation 64 may be rewritten:

$$
\frac{a_{3}}{\gamma_{4}-1}>\frac{a_{2}}{\gamma_{1}-1}
$$

Looking back at Equation 25, one promptly sees that the simplest way to ensure this condition is by adjustment of the molecular weights of the gases. Driver gases are normally hydrogen or helium, while reactants are diluted in argon or nitrogen. Nevertheless, the determination of the cooling effect is best done experimentally rather than simply resorting to ideal theory.

The equations derived in this section, though not of conputational value in kinetics experiments, give an excellent picture of shock tube phenomena. In general, the reactants in a shock tube are diluted with inert gas to the extent that these equations provide a reasonable first approximation to shock tube conditions. However, for the accurate determination of temperature that is mandatory in kinetics experiments: the equations of this section are not sufficient. 
B. Application to Real Gases with Chemical Reaction

The objective of this section is to outline the proper forms of the shock tube equations as applied to the isotopic. exchange of iodine and methyl iodide. It is hoped that the technique demonstrated here may serve as a guide for the solution of more complex systems. The overriding simplification of the present problem is that the reactants and products are the same. Thus, there is no need to know the extent of reaction behind the incident or reflected shock waves since there is no heat of reaction and no change in number of moles. However, iodine dissociation is quite extensive behind the reflected shock wave and must be taken into consideration.

For the system argon, iodine, and methyl iodide, the following relationships are simply derived from the ideal gas law, assuming no reaction behind the incident shock:

$$
\begin{aligned}
M_{1} & =x_{A} M_{A}+x_{R I} M_{R I}+x_{I_{2}} M_{I_{2}}, \\
M_{2} & =M_{1}, \\
M_{5} & =\frac{x_{A} M_{A}+X_{R I} M_{R I}+x_{I_{2}} M_{2}}{1+\emptyset X_{2}}, \\
P_{21} & =M_{12} \Gamma_{21} T_{21}=\Gamma_{21} T_{21},
\end{aligned}
$$

and

$$
P_{52}=M_{25} \Gamma_{52} T_{52}=\left(1+\emptyset x_{I_{2}}\right) \Gamma_{52} T_{52}
$$


Writing Equation 27 in a more convenient fashion one obtains.

$$
\mathrm{h}_{2}-\mathrm{h}_{1}=\frac{1}{2} \frac{\mathrm{p}_{1}}{\mathrm{p}_{1}}\left(\mathrm{P}_{21}-1\right)\left(1+\frac{1}{\Gamma_{21}}\right) \text {. }
$$

Since Equation 28 does not apply, in general, one must obtain the enthalpies from standard tables or by use of appropriate partition functions. By substitution of Equations 23 and 70 , Equation 72 becomes:

$$
\mathrm{h}_{2}-\mathrm{h}_{1}=\frac{1}{2} \frac{\mathrm{RT}_{1}}{\mathrm{M}_{1}}\left[\mathrm{P}_{21}-1\right]\left[1+\frac{\mathrm{T}_{21}}{\mathrm{P}_{21}}\right] \text {. }
$$

Multiplying the left side of this equation by $M_{1}$, the following reduction occurs:

$$
\begin{aligned}
& \left(\mathrm{h}_{2}-\mathrm{h}_{1}\right) \mathrm{M}_{1}=\mathrm{M}_{12} \mathrm{H}_{2}^{\mathrm{O}}-\mathrm{H}_{1}^{\mathrm{O}}=\mathrm{H}_{2}^{\mathrm{O}}-\mathrm{H}_{1}^{\mathrm{O}} \\
& =\mathrm{X}_{\mathrm{A}} \mathrm{H}_{\mathrm{A}, 2}^{\mathrm{O}}+\mathrm{X}_{\mathrm{RI}} \mathrm{H}_{\mathrm{RI}, 2}^{\mathrm{O}}+\mathrm{x}_{\mathrm{I}_{2}} \mathrm{H}_{\mathrm{I}_{2}, 2}^{\mathrm{O}} \\
& \text { - } \mathrm{X}_{\mathrm{A}} \mathrm{H}_{\mathrm{A}, 1}^{\mathrm{O}}-\mathrm{X}_{\mathrm{RI}} \mathrm{H}_{\mathrm{RI}, 1}^{\circ}-\mathrm{x}_{\mathrm{I}_{2}} \mathrm{H}_{\mathrm{I}_{2,1}}^{\mathrm{O}} \\
& =\mathrm{X}_{\mathrm{A}}\left[\left(\mathrm{H}^{\mathrm{O}}-\mathrm{H}_{\mathrm{O}}^{\mathrm{O}}\right)_{\mathrm{A}, 2}-\left(\mathrm{H}^{\mathrm{O}}-\mathrm{H}_{\mathrm{O}}^{\mathrm{O}}\right)_{\mathrm{A}, 1}\right]+\mathrm{X}_{\mathrm{RI}}\left[\left(\mathrm{H}^{\mathrm{o}}-\mathrm{H}_{\mathrm{O}}^{\mathrm{O}}\right)_{\mathrm{RI}, 2}\right. \\
& \text { - } \left.\left(\mathrm{H}^{\mathrm{o}}-\mathrm{H}_{\mathrm{O}}^{\mathrm{O}}\right)_{\mathrm{RI}, 1}\right]+\mathrm{X}_{\mathrm{I}_{2}}\left[\left(\mathrm{H}^{\mathrm{O}}-\mathrm{H}_{\mathrm{O}}^{\mathrm{O}}\right)_{I_{2}, 2}-\left(\mathrm{H}^{\mathrm{o}}-\mathrm{H}_{\mathrm{O}}^{\mathrm{O}}\right)_{\left.I_{2,1}\right]}\right. \text {. }
\end{aligned}
$$

This equation replaces the much simpler relation, Equation 28. The function $\mathrm{H}^{\circ} \mathrm{H}_{\mathrm{O}}^{\circ}$ is not adaptable to linear interpolation so the following rearrangement is made on Equation 73: 


$$
\begin{aligned}
& \frac{2\left(\mathrm{~h}_{2}-\mathrm{h}_{1}\right) \mathrm{M}_{1}}{\mathrm{RT}_{1}}=\left[\mathrm{P}_{21}-1\right]\left[1+\frac{\mathrm{T}_{21}}{\mathrm{P}_{21}}\right] \\
& =X_{A}\left[\frac{2}{R} T_{21}\left(\frac{H^{O}-H_{O}^{O}}{T}\right)_{A, 2}-\frac{2}{R}\left(\frac{H^{O}-H_{O}^{O}}{T}\right)_{A, 1}\right] \\
& +\mathrm{X}_{\mathrm{RI}}\left[\frac{2}{\mathrm{R}} \mathrm{T}_{21}\left(\frac{\mathrm{H}^{\mathrm{O}}-\mathrm{H}_{\mathrm{O}}^{\mathrm{O}}}{\mathrm{T}}\right)_{\mathrm{RI}, 2}-\frac{2}{\mathrm{R}}\left(\frac{\mathrm{H}^{\mathrm{O}}-\mathrm{H}_{\mathrm{O}}^{\mathrm{O}}}{\mathrm{T}}\right)_{\mathrm{RI}, 1}\right] \\
& +\mathrm{X}_{\mathrm{I}_{2}}\left[\frac{2}{\mathrm{R}} \mathrm{T}_{21}\left(\frac{\mathrm{H}^{\mathrm{O}}-\mathrm{H}_{\mathrm{O}}^{\mathrm{O}}}{\mathrm{T}}\right)_{\mathrm{I}_{2}, 2}-\frac{2}{\mathrm{R}}\left(\frac{\mathrm{H}^{\mathrm{O}}-\mathrm{H}_{\mathrm{O}}^{\mathrm{O}}}{\mathrm{T}}\right)_{\mathrm{I}_{2}, 1}\right] \text {. }
\end{aligned}
$$

The enthalpy functions in Equation 75 are known to behave linearly with temperature and can be readily interpolated between the usual $100^{\circ} \mathrm{C}$ intervals of standard tabulations. Another simplification is introduced by making the following change in functional dependence:

$$
\frac{2}{R}\left(\frac{\mathrm{H}^{\mathrm{O}}-\mathrm{H}_{\mathrm{O}}^{\mathrm{O}}}{\mathrm{T}}\right)-\frac{2}{\mathrm{R}}\left(\frac{\mathrm{H}^{\mathrm{O}}-\mathrm{H}_{\mathrm{O}}^{\mathrm{O}}}{\mathrm{T}}\right)-1 \text {. }
$$

Equation 75 then becomes:

$$
\begin{aligned}
\mathrm{P}_{21} & =\mathrm{T}_{21} / \mathrm{P}_{21} \\
& +\mathrm{X}_{\mathrm{A}}\left\{\mathrm{T}_{21}\left[\frac{2}{\mathrm{R}}\left(\frac{\mathrm{H}^{\mathrm{O}}-\mathrm{H}_{\mathrm{O}}^{\mathrm{O}}}{\mathrm{T}}\right)-1\right]_{\mathrm{A}, 2}-\left[\frac{2}{\mathrm{R}}\left(\frac{\mathrm{H}^{\mathrm{O}}-\mathrm{H}_{\mathrm{O}}^{\mathrm{O}}}{\mathrm{T}}\right)-1\right]_{\mathrm{A}, 1}\right\} \\
& +\mathrm{X}_{\mathrm{RI}}\left\{\mathrm{T}_{21}\left[\frac{2}{\mathrm{R}}\left(\frac{\mathrm{H}^{\mathrm{O}}-\mathrm{H}_{\mathrm{O}}^{\mathrm{O}}}{\mathrm{T}}\right)-1\right]_{\mathrm{RI}, 2}-\left[\frac{2}{\mathrm{R}}\left(\frac{\mathrm{H}^{\mathrm{O}}-\mathrm{H}_{\mathrm{O}}^{\mathrm{O}}}{\mathrm{T}}\right)-1\right]_{\mathrm{RI}, 1}\right\} \\
& +\mathrm{XI}_{2}\left\{\mathrm{~T}_{21}\left[\frac{2}{\mathrm{R}}\left(\frac{\mathrm{H}^{\mathrm{O}}-\mathrm{H}_{\mathrm{O}}^{\mathrm{O}}}{\mathrm{T}}\right)-1\right]_{\mathrm{I}_{2}, 2}-\left[\frac{2}{\mathrm{R}}\left(\frac{\mathrm{H}^{\mathrm{O}}-\mathrm{H}_{\mathrm{O}}^{\mathrm{O}}}{\mathrm{T}}\right)-1\right]_{\mathrm{I}_{2}, 1}\right\}
\end{aligned}
$$

For a given value of $\mathrm{T}_{21}$ Equation 76 is a simple quadratic in $P_{21}$. The enthalpy functions are tabulated linear functions of temperature in $100^{\circ} \mathrm{C}$ intervals. 
From Equation 33 we may immediately write:

$$
\mathrm{U}_{\mathrm{I}}^{2}=\frac{\mathrm{P}_{1}}{\mathrm{P}_{1}}\left(\frac{1-\mathrm{P}_{21}}{1 / \Gamma_{21}-1}\right)=\frac{\mathrm{RT}_{1}}{\mathrm{M}_{1}}\left(\frac{\mathrm{P}_{21}-1}{1-\mathrm{T}_{21} / \mathrm{P}_{21}}\right) .
$$

For a given value of $\mathrm{T}_{21}$ and $\mathrm{U}_{\mathrm{I}}$ Equation 77 is a simple quadratic in $P_{21}$. Equations 76 and 77 serve to uniquely determine the state behind the incident shock wave. Thus, one measures the incident shock velocity and allows $\mathrm{T}_{21}$ to vary until Equations 76 and 77 are in agreement.

Using the reflected shock wave as a reference, one may write the conservation equations as follows:

$$
\begin{aligned}
& \rho_{2}\left(U_{R}+u_{2}\right)=\rho_{5} U_{R}, \\
& h_{2}+\frac{1}{2}\left(U_{R}+u_{2}\right)^{2}=h_{5}+\frac{1}{2} U_{R}{ }^{2}, \\
& p_{2}+\rho_{2}\left(U_{R}+u_{2}\right)^{2}=p_{5}+\rho_{5} U_{R}{ }^{2} .
\end{aligned}
$$

By analogy with the derivation of Equation 76, taking into account dissociation, one obtains:

$$
\begin{aligned}
\mathrm{P}_{52} & =\left(1+\emptyset \mathrm{X}_{\mathrm{I}_{2}}\right) \mathrm{T}_{52} / \mathrm{P}_{52} \\
& +\mathrm{X}_{\mathrm{A}}\left\{\mathrm{T}_{52}\left[\frac{2}{\mathrm{R}}\left(\frac{\mathrm{H}^{\mathrm{O}}-\mathrm{H}_{\mathrm{O}}^{\mathrm{O}}}{\mathrm{T}}\right)-1\right]_{\mathrm{A}, 5}-\left[\frac{2}{\mathrm{R}}\left(\frac{\mathrm{H}^{\circ}-\mathrm{H}_{\mathrm{O}}^{\mathrm{O}}}{\mathrm{T}}\right)-1\right]_{\mathrm{A}, 2}\right\} \\
& +\mathrm{X}_{\mathrm{RI}}\left\{\mathrm{T}_{52}\left[\frac{2}{\mathrm{R}}\left(\frac{\mathrm{H}^{\circ}-\mathrm{H}_{\mathrm{O}}^{\mathrm{O}}}{\mathrm{T}}\right)-1\right]_{\mathrm{RI}, 5}-\left[\frac{2}{\mathrm{R}}\left(\frac{\mathrm{H}^{\circ}-\mathrm{H}_{\mathrm{O}}^{\circ}}{\mathrm{T}}\right)-1\right]_{\mathrm{RI}, 2}\right\} \\
& +\mathrm{X}_{\mathrm{T}_{2}}\left\{(1-\emptyset) \mathrm{T}_{52}\left[\frac{2}{\mathrm{R}}\left(\frac{\mathrm{H}^{\mathrm{O}}-\mathrm{H}_{\mathrm{O}}^{\mathrm{O}}}{\mathrm{T}}\right)-1\right]_{\mathrm{I}_{2}, 5}-\left[\frac{2}{\mathrm{R}}\left(\frac{\mathrm{H}^{\circ}-\mathrm{H}_{\mathrm{O}}^{\mathrm{O}}}{\mathrm{T}}\right)-1\right]_{\mathrm{I}_{2}, 2}\right. \\
& \therefore+2 \emptyset \mathrm{T}_{52}\left[\frac{2}{\mathrm{~K}}\left(\frac{\mathrm{H}^{\circ}-\mathrm{H}_{\mathrm{O}}^{\mathrm{O}}}{\mathrm{T}}\right)-1\right]_{\mathrm{I}, 5}+2 \emptyset \frac{\Delta \mathrm{H}_{\mathrm{O}}^{\mathrm{O}}}{\mathrm{RT}_{2}}
\end{aligned}
$$


The term $\Delta \mathrm{H}_{\mathrm{O}}^{\mathrm{O}}$ represents the enthalpy change at absolute zero for the dissociation of one mole of iodine molecules. The one remaining equation necessary to complete the analysis is evolved in the following manner. Substitution of Equation 78 into Equation 80 yields the following:

$$
\mathrm{U}_{\mathrm{R}}^{2}=\frac{\mathrm{p}_{2}}{\rho_{5}}\left(\frac{\mathrm{P}_{52}-1}{\Gamma_{52}-1}\right)=\frac{\mathrm{RT}_{2}}{\mathrm{M}_{2}}\left(\frac{1}{\Gamma_{52}}\right)\left(\frac{\mathrm{P}_{52}-1}{\Gamma_{52}-1}\right) .
$$

Now, $U_{R}$ can be related to $U_{I}$ by elimination of $u_{2}$ from Equations 78 and 20. Thus,

$$
\begin{gathered}
u_{2}=\frac{\rho_{5}-\rho_{2}}{\rho_{2}} U_{R}=\left(\Gamma_{52}-1\right) U_{R}, \\
u_{2}=\frac{\rho_{2}-\rho_{1}}{\rho_{2}} U_{I}=\left(1-1 / \Gamma_{21}\right) U_{I} .
\end{gathered}
$$

Eliminating $u_{2}$ from the last two equations:

$$
\mathrm{u}_{\mathrm{R}}^{2}=\mathrm{U}_{\mathrm{I}}^{2}\left[\frac{1-1 / \Gamma_{21}}{\Gamma_{52}-1}\right]^{2} \text {. }
$$

Substitution in Equation 82 yields the final relation:

$$
\mathrm{U}_{\mathrm{I}}^{2}\left(1-1 / \Gamma_{21}\right)^{2}=\frac{\mathrm{RT}_{2}}{\mathrm{M}_{2}}\left(\frac{1}{\Gamma_{52}}\right)\left(\mathrm{P}_{52^{-1}}\right)\left(\Gamma_{52^{-1}}\right)
$$

Rewritten using the ideal gas law, this becomes:

$$
\mathrm{U}_{\mathrm{I}}{ }^{2}\left(1-\mathrm{T}_{21} / \mathrm{P}_{21}\right)^{2}=\frac{\mathrm{RT}_{2}}{\mathrm{M}_{1}}\left(\mathrm{P}_{52}-1\right)\left[1-(1+\emptyset) \frac{\mathrm{T}_{52}}{\mathrm{P}_{52}}\right] \text {. }
$$


Equations 81 and 87 serve to uniquely define the state of the gas behind the retlected wave from a knowledge of $\mathrm{T}_{2}, \mathrm{p}_{2}$, and the incident shock velocity. Since the degree of dissociation is itself a function of temperature and pressure the last equation must be solved by an iterative process. As before, Equations 81 and 87 are solved simultaneously by varying $T_{52}$ and solving the quadratics for $\mathrm{P}_{52}$. This technique of solution is rapidly handled by a digital computer. 


\section{EXPERIMENTAL}

\section{A. Chemicals}

Grade-A helium, used as the driver gas in the shock tube, was supplied by the Department of the Interior, Bureau of Mines. Argon, used as the diluent in the reactant section, was supplied by Air Products and Chemicals, Inc. Both gases had a minimum purity of $99.995 \%$ and were used without further purification.

The methyl iodide used in the experiment was. Baker's Analytical Reagent grade. The only treatment performed on the iodide was passage through a column of anhydrous silica gel. Harris and Willard (41) demonstrated that methyl iodide so treated yields the same infrared spectrum as that obtained after repeated fractional distillation. The methyl iodide was stored in a darkened flask with a strip of copper wire to prevent decomposition.

$\mathrm{I}^{131}$ was procured from Cambridge Nuclear Corp. It was supplied as the aqueous iodide, carrier free, in basic solution. A predetermined amount of Baker's Analytical Reagent grade potassium iodide was dissolved in an aliquot of the active iodide solution. The solution was acidified with nitric acld until precipitation of the iodine was complete. The solid 
was filtered and sublimed.

\section{B. Apparatus}

The shock tube built for the present experiment, similar to that used by Lifshitz, Bauer, and Resler (17), is illustrated in Figure 9. With the exception of the copper foil, all metal parts in contact with the interior of the shock tube were fabricated from stainless steel. Because of the low shock velocities in the experiments, the driver section was slightly longer than it would be for high temperature experiments. The length of the driver section was made adjustable by placing a piston on the end of a threaded rod. The piston was machined to the point where its diameter allowed it to pass through the Pyrex tube without scratching it. Discussion of the tuning of the shock tube is found in the next section. The Pyrex pipe was obtained from Corning Glass Works, and is known as 'Double-Tough', No. 7740. The pipe is provided with tight fitting Teflon gaskets, which were used for all the glass-metal joints. The end of the driver section consisted of a short stainless steel cylinder. An outlet on the cylinder served for both evacuation of the driver section and the admission of helium. The plunger consisted of a stainless steel. needle mounted on the bottom of a sealed bellows valve. 


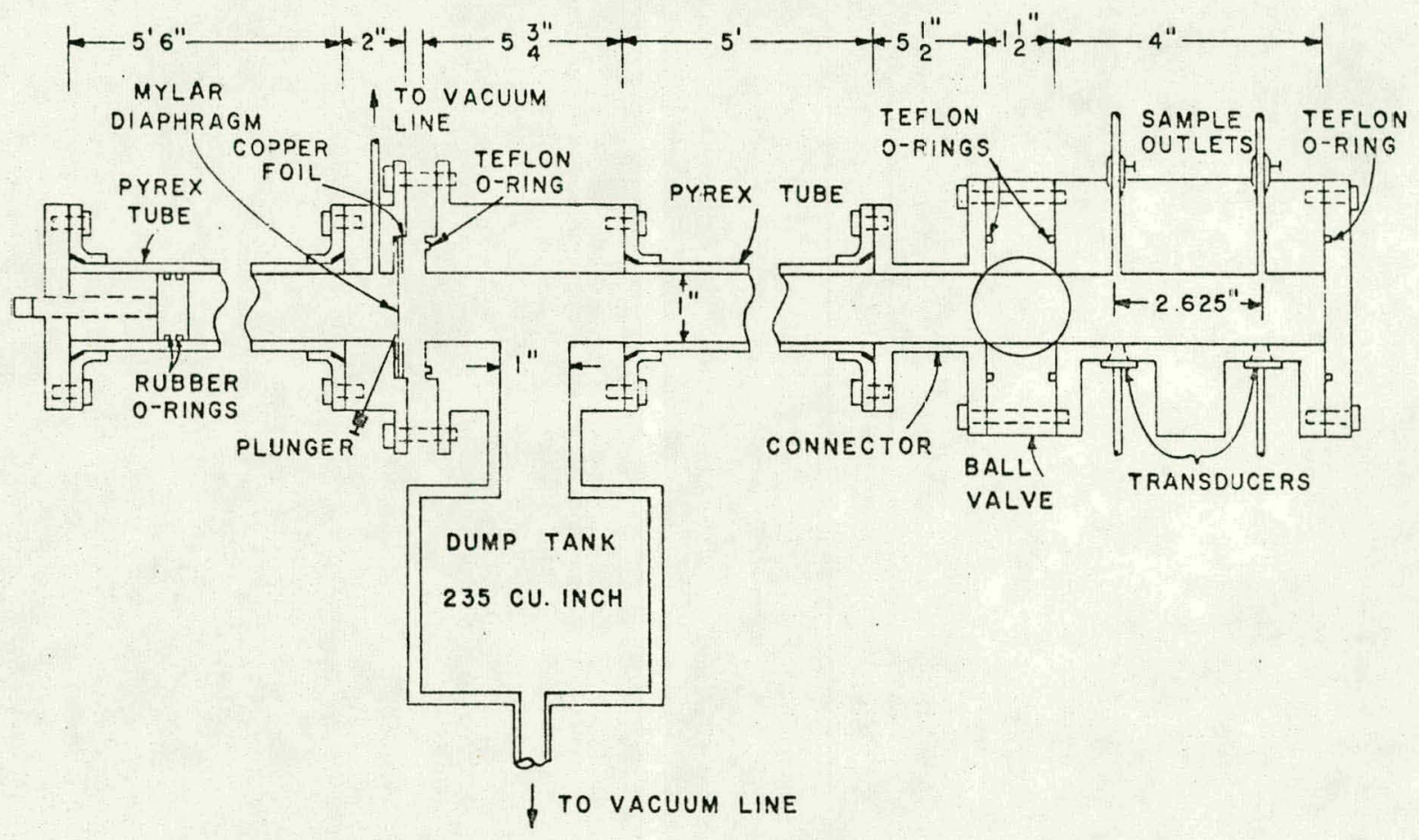

Figure 9. The single-pulse chemical shock tube used for the $\mathrm{CH}_{3} \mathrm{I}-\mathrm{I}_{2}$ exchange 
The end of the driver section was recessed so that the connector following. it could be made to tightly enclose the diaphragm. The diaphragm was placed in the recess with a copper foil on top of it. The seal arose from the pressure of a Teflon 0-ring pressed against the copper foil. The connector, and the dump tank to which it was welded, were both of stainless steel. The bottom of the dump tank led through a cold trap to the vacuum line. Evacuation of the reactant section and removal of unreacted gases was performed through this line. The major portion of the reactant section consisted of a long section of Pyrex pipe. A short stainless steel connector was added to adapt the flange on the Pyrex pipe to the screw holes drilled in the ball valve. The ball valve, obtained from Worcester Sprinkler Co., was one of the only valves manufactured with a uniform bore. The valve was closed immediately after the diaphragm burst to prevent the mixing of cold gases with the reacted gases. Figure 2 demonstrates that the gases remaining downstream of the ball valve have been at reaction temperature the 1ongest. At the end of the reactant section the two transducers were located a fixed distance apart. Kistler Quartz Pressure Transducers, Model 601A, were. each connected directly to Kistler Electrostatic Charge Ampli- 
fiers, Model 566. The amplifier outputs were connected in parallel and fed to the external triggering circuit of a Tektronix Oscilloscope, Type 535. The input was then led through a magnetic delay line, with a $6.5 \mathrm{\mu sec}$ delay, to the vertical input of a Tektronix Preamp, Type $\mathrm{K}$. The oscilloscope was provided with a raster sweep circuit, Tektronix Modification 118. This allowed a significant time expansion on the oscilloscope screen. A Tektronix Time Marker, Type 181, was used to provide $10 \mu \mathrm{sec}$. time marks which were superimposed on the signal from the charge amplifiers. The oscilloscope was set for single sweep horizontal display and. the raster, triggered by the incident shock, was photographed with a Tektronix Camera, Type C-12. Photographs of typical sweeps, both with and without a signal from the charge amplifiers, are illustrated in Figure 10. It should be mentioned that signals caused by the natural frequencies of the transducers were removed in the most part by electronic filters. This filtering system caused the small oscillations appearing immediately after each shock pulse in Figure 10b. In addition, the timing switch circuits of the raster sweep generator were modified so that the sweep rates could be made continuously variable. As supplied from the factory, the raster 


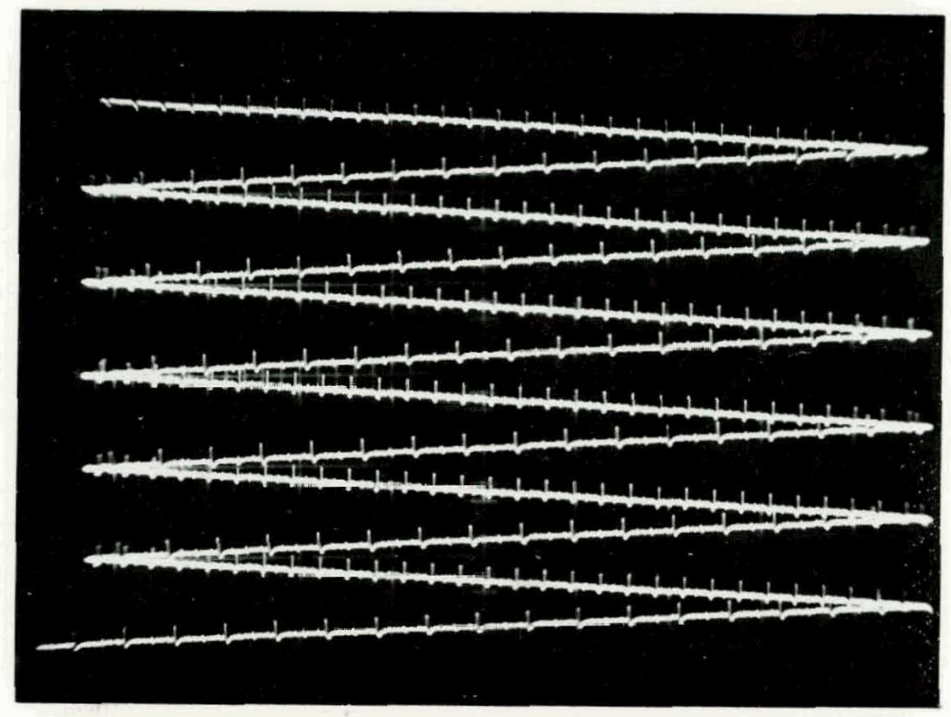

Figure 10a. Free running trace of the output of the raster sweep circuit

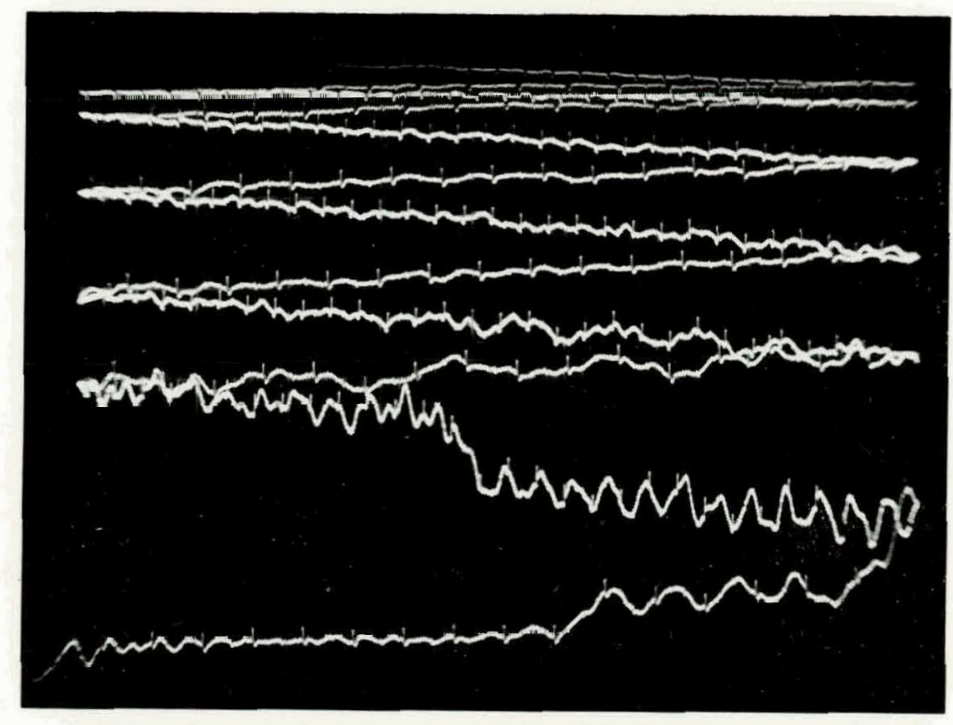

Figure 10b. Same as above, with typical shock tube output from transducers and time marks superimposed 
sweep modification allows only a fixed number of precalibrated sweep rates.

The sample outlets in the end section were connected to the vacuum line and sample bulbs, as illustrated in Figure 11. After addition of methy 1 iodide to the $25 \mathrm{~m} 1$. sample bulb, the large tank was evacuated to below one micron while the iodide was frozen at liquid nitrogen temperature. The iodide was then allowed to vaporize into the tank and its pressure was read on a Wallace and Tiernan Absolute Pressure Gauge, Mode1 FA-160. Argon was then admitted to the tank to the desired pressure, as determined by a mercury manometer. The gases were allowed to further mix for a day. To begin each experiment a sample of solid iodine was weighed out in the 10 m1. sample bulb. While the iodine was kept at liquid nitrogen temperature, the 31 . mixing bulb and the $10 \mathrm{ml}$. sample bulb were evacuated through the sample outlets. The iodine was then sublimed into the large mixing bulb. The iodine pressure was calculated on the assumption that it obeyed the ideal gas law, the exact volume of the mixing bulb assembly having been previously determined. The 31 . bulb and the driver section of the shock tube, including the dump tank, were heated to $335 \pm 2^{\circ} \mathrm{K}$ to ensure complete sublimation of 


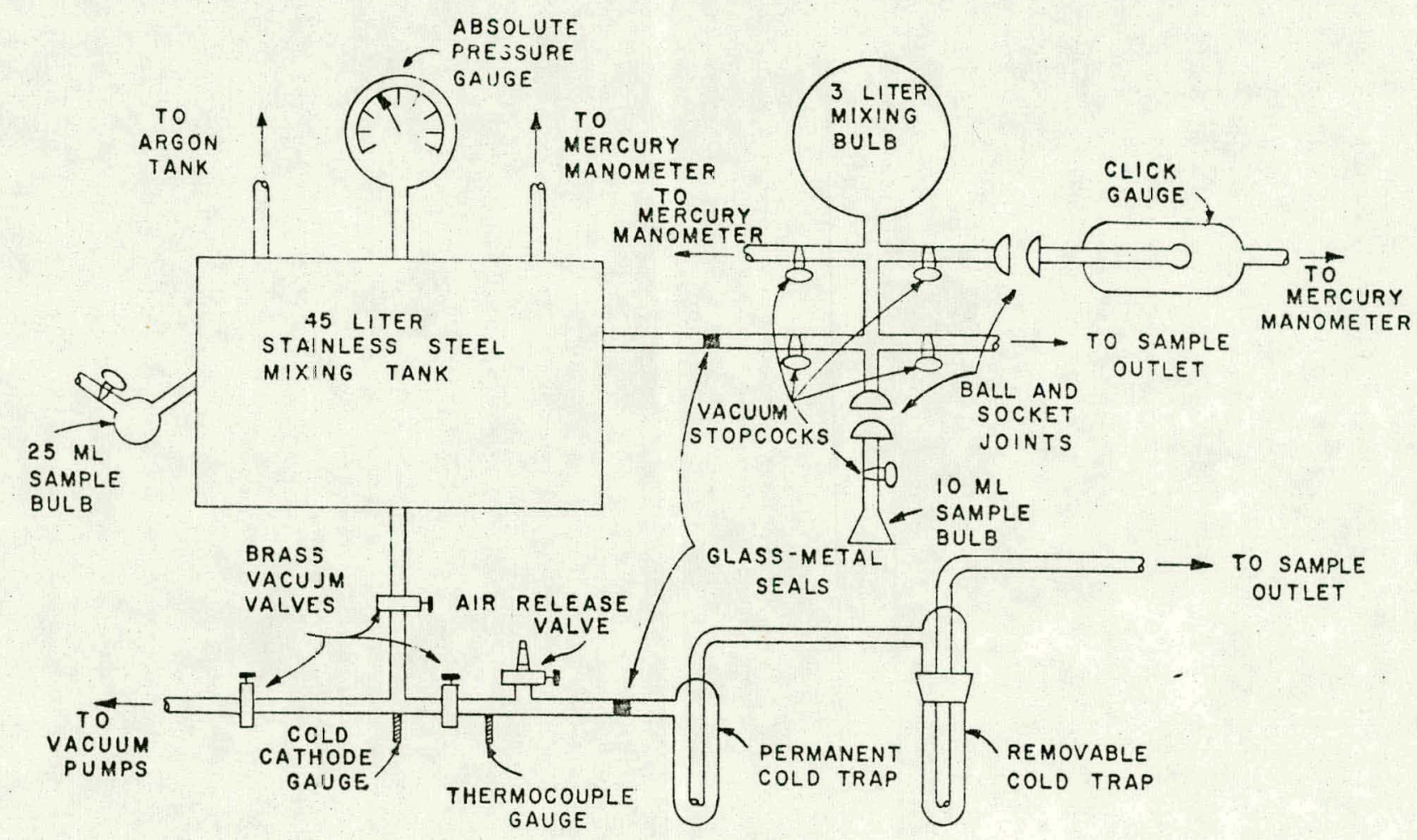

Figure 11. Apparatus used for sample preparation and removal from shock tube 
the iodine. The argon-methyl iodide mixture was then admitted to the mixing bulb and the total bulb pressure was measured indirectly, by use of a click gauge in line with a mercury manometer. The click gauge, a small bulb blown at the end of a short length of glass tubing, gives an audible and visible click at some constant pressure difference across the gauge face. The additional manometer on the mixing bulb was used for calibration of the click gauge. To prevent the deposit of solid iodine, the click gauge was maintained at the same elevated temperature as the shock tube. The principal reason for using this device was that no direct pressure reading instrument was found suitable for use with iodine vapor. After the gases were mixed they were admitted to the shock tube and the pressure again determined with the click gauge. After an experiment the products were pumped into the removable liquid $\mathrm{N}_{2}$ cooled trap.

After separation of the reactants, their $y$-ray activity was determined on a Radiation Instrument Development Laboratory 400 Channel Analyzer, Model 34-12B. The technique effectively indicated the fraction of exchange for each experiment. 


\section{Procedures}

Before performing any kinetics experiments in the shock tube it was necessary to tune the instrument for the combin. ation of the helium driver and heated argon driven section. By tuning of the shock tube is meant the arrangement of the length of the tube such that the reflected far-end expansion wave and the reflected shock wave meet at the contact surface. This phenomenon was discussed in Section II-A. The tuning is accomplished by operating the shock tube under the conditions of the kinetics experiment to be studied. A photograph of the oscilloscope trace of such an experiment, without raster sweep, is shown in Figure 12a. The hump in the cooling curve indicates the late arrival of the reflected far-end expansion wave. Figure $12 \mathrm{~b}$ demonstrates the sharp cooling curve brought about by tuning the shock tube.

The preparation of the reactant gas sample was discussed in the previous section. Before the reactants were admitted into the shock tube, a Mylar diaphragm was inserted in place, and the driver and reactant sections were evacuated, the latter to below $10^{-3}$ torr pressure. The driver section was filled to the desired pressure with helium, and the diaphragtm was then punctured with the plunger. The ball valve was 


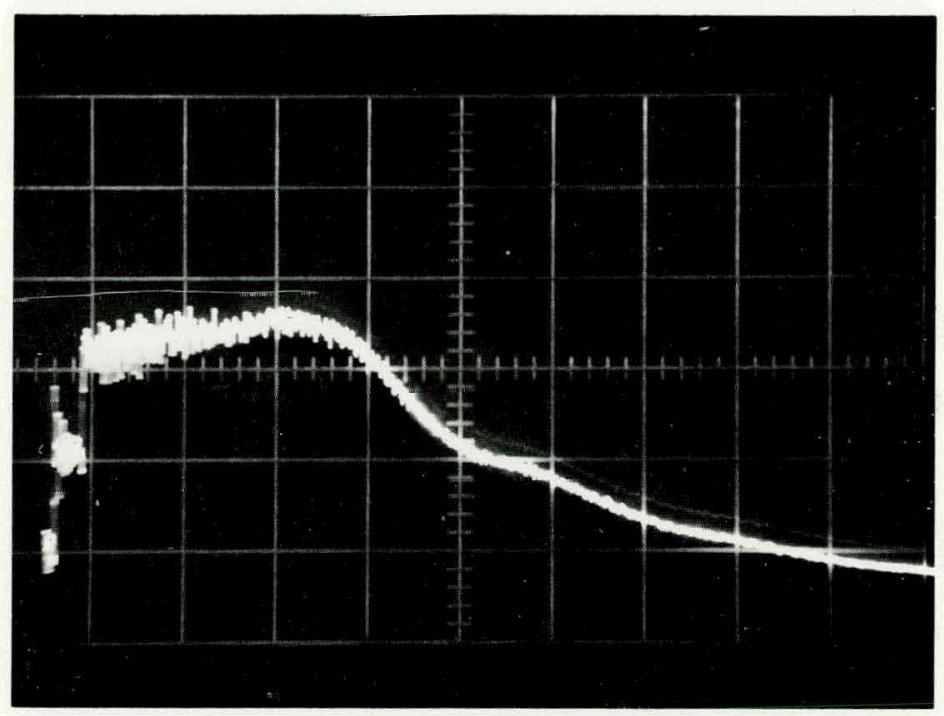

(a)

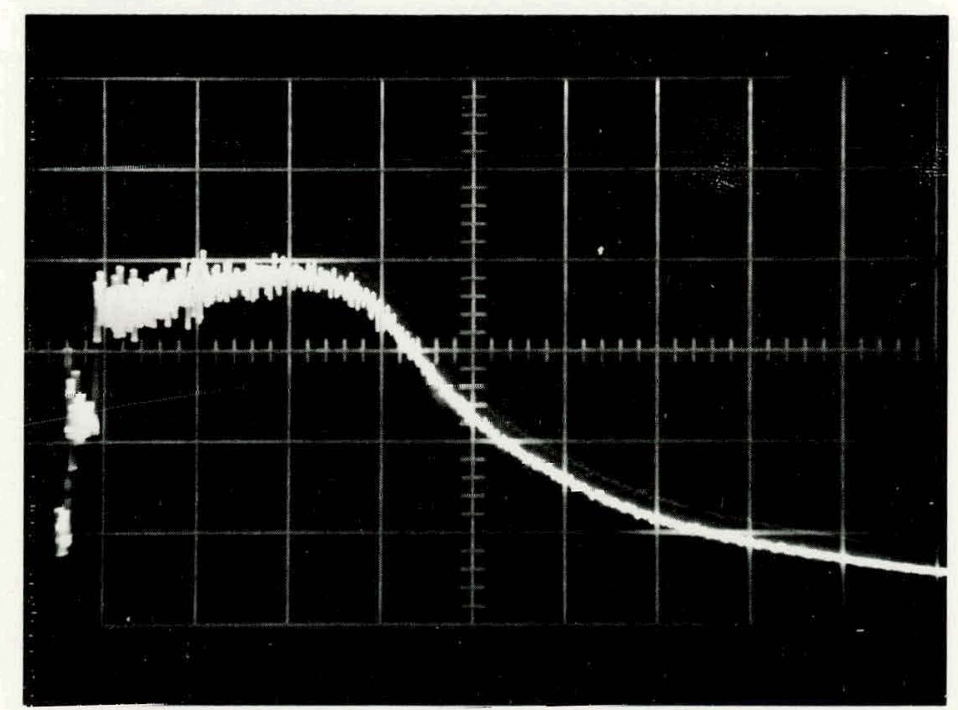

(b)

Figure 12. Successive photographs taken before and after tuning the driver section of the shock tube 
immediately closed to separate the reacted gases from the cold portion of the shock tube. The photograph of the oscilloscope screen was developed in the next few seconds from the Polaroid back on the oscilloscope camera. The reactants were then pumped out of the shock tube and collected in a liquid $\mathrm{N}_{2}$ cooled trap. They were diluted with acetone and shaken with a small drop of mercury until the reduction of iodine was completed. A hot water bath was sufficient to distill the organic products and leave the inorganic iodide behind. The samples were counted in plastic vials, the organic materials made up to volume with acetone, the inorganic iodide made up to volume with a $10 \%$ sodium iodide solution.

The counting of the products was performed by counting the 46 channels that contained the main $\gamma$-ray peak at 0.3645 Mev. The error in counting is given by the standard relation:

$$
\sigma=\frac{\sqrt{c}}{c}
$$

where $c$ is the total number of counts. To reduce the error, at least 10,000 counts were accumulated for each sample. The fraction of exchange, $F$, is given by the simple formula:

$$
F=\frac{c_{R I}}{c_{R I}+c_{T_{2}}} \frac{X_{R I}+2 X_{I_{2}}}{x_{R I}}
$$


where: $\quad C_{R I}=$ counts from methyl iodide sample;

$$
\mathrm{c}_{\mathrm{I}_{2}}=\text { counts from inorganic iodide sample. }
$$

A complete error analysis of the shock tube experiment wil1 not be attempted here. For the temperature range of interest in this study many investigators have shown the uncertainty in temperature to be of the order of $1-2 \%$. Other errors in the determination will be treated as they become apparent. 


\section{CALCULATIONS}

A. Determination of Reaction Parameters

For any given experiment, the laboratory velocity of the incident shock wave, along with the initial conditions, provided sufficient information for the solution of Equations 76, 77, 81, and 87. The algebra and iterations were performed on an IBM $360 / 65$ digital computer. Before discussing the computational methods, it is necessary to outline some of the assumptions contained therein.

The various thermodynamic functions for argon, iodine, and iodine atoms are tabulated in the JANAF Thermochemical Tables (42). However, no tabulations are available for methyl iodide. Since the concentration of methy 1 iodide in the experiments was small, it was felt that calculation of entha1pies and heat capacities from classical partition functions, without the use of any anharmonicity corrections, would introduce negligible error into the result. Fundamental vibrational frequencies of methyl iodide were found in Sponer (43), and are given in Table 1 . The enthalpy function, $\left(\mathrm{H}^{\mathrm{O}} \mathrm{H}_{\mathrm{O}}^{\mathrm{O}} / \mathrm{T}\right)$, and the heat capacity; $c_{p}^{\circ}$, were calculated from the following formulas, which are found in Lewis and Randall (44, Chapter 27): 
Table 1. - Fundamental frequencies of methyl iodide

\begin{tabular}{cc}
$\begin{array}{c}\text { Fundamental frequency } \\
\mathrm{cm}-1\end{array}$ & Degeneracy \\
\hline 3074 & 2 \\
1445 & 2 \\
885 & 2 \\
2916 & 1 \\
1252 & 1 \\
532 & 1 \\
\hline
\end{tabular}

$$
\begin{aligned}
\frac{\mathrm{H}^{\mathrm{O}}-\mathrm{H}_{\mathrm{O}}^{\mathrm{O}}}{\mathrm{T}} & =R\left\{4+\sum_{i} \frac{\mathrm{hc} \nu_{i}}{\mathrm{kT}} \frac{1}{\exp \left(\mathrm{hc} \nu_{i} / \mathrm{kT}\right)-1}\right\} \\
\mathrm{C}_{\mathrm{p}}^{\mathrm{O}} & =\mathrm{R}\left\{4+\sum_{i} \frac{\mathrm{hc} \nu_{i}}{\mathrm{kT}} \frac{\exp \left(h c \nu_{i} / \mathrm{kT}\right)}{\left[\exp \left(\mathrm{hc} \nu_{i} / \mathrm{kT}\right)-1\right]^{2}}\right\}
\end{aligned}
$$

where: $h$ is Planck's constant;

c is the speed of light;

$\mathrm{k}$ is Boltzmann's constant;

$\nu_{i}$ is fundamental frequency in $\mathrm{cm} .{ }^{-1}$.

The heat capacities calculated here are in agreement with the low temperature heat capacities calculated by Edgell and Glockler (45). Values of the functions $\left(\mathrm{H}^{\circ}-\mathrm{Hl}_{\mathrm{O}}^{\circ}\right) / \mathrm{T}$ and $2\left(\mathrm{H}^{\circ}-\mathrm{H}_{\mathrm{O}}^{\circ}\right) / \mathrm{RT}-1$ are tabulated in Table 2 for $\mathrm{A}_{\mathrm{r}}, \mathrm{I}_{2}, \mathrm{I}$ and $\mathrm{CH}_{3} \mathrm{I}$ over the temperatures of interest in this experiment. Heat capacities are tabulated in Table 3 and are used in the following section. Both enthalpy functions of Table 2 are 
Table 2. Enthalpy functions of $\mathrm{A}_{\mathrm{r}}, \mathrm{I}_{2}, \mathrm{I}$, and $\mathrm{CH}_{3} \mathrm{I}$

\begin{tabular}{|c|c|c|c|c|c|c|c|c|}
\hline \multirow[t]{2}{*}{$\begin{array}{c}\text { Temperature } \\
\mathrm{O}_{\mathrm{K}}\end{array}$} & \multicolumn{4}{|c|}{$\frac{\mathrm{H}^{\mathrm{O}}-\mathrm{H}_{\mathrm{O}}^{\mathrm{O}}}{\mathrm{T}}$} & \multicolumn{4}{|c|}{$\frac{2}{\mathrm{R}}\left(\frac{\mathrm{H}^{\mathrm{O}}-\mathrm{H}_{\mathrm{O}}^{\mathrm{O}}}{\mathrm{T}}\right)$} \\
\hline & $A_{r}$ & $\mathrm{I}_{2}$ & $I$ & $\mathrm{CH}_{3} \mathrm{I}$ & $A_{r}$ & $I_{2}$ & I & $\mathrm{CH}_{3} \mathrm{I}$ \\
\hline $\begin{array}{r}335 \\
400 \\
500 \\
600 \\
700 \\
800 \\
900 \\
1000 \\
1100 \\
1200 \\
1300 \\
1400\end{array}$ & 4.968 & $\begin{array}{l}8.181 \\
8.301 \\
8.426 \\
8.516 \\
8.584 \\
8.638 \\
8.682 \\
8.719 \\
8.750 \\
8.778 \\
8.803 \\
8.285\end{array}$ & $\begin{array}{c}\downarrow \\
4.969 \\
4.969 \\
4.970 \\
4.971\end{array}$ & $\begin{array}{c}8.900 \\
9.371 \\
10.12 \\
10.87 \\
11.58 \\
12.25 \\
12.88 \\
13.47 \\
14.02 \\
14.53 \\
15.01 \\
15.45\end{array}$ & $\left.\right|^{4.000}$ & $\begin{array}{l}7.233 \\
7.354 \\
7.480 \\
7.571 \\
7.639 \\
7.693 \\
7.738 \\
7.775 \\
7.806 \\
7.834 \\
7.859 \\
7.881\end{array}$ & $\begin{array}{c} \\
4.001 \\
4.002 \\
4.003\end{array}$ & $\begin{array}{l}7.957 \\
8.431 \\
9.185 \\
9.940 \\
10.65 \\
11.33 \\
11.96 \\
12.56 \\
13.11 \\
13.62 . \\
14.11 \\
14.55\end{array}$ \\
\hline
\end{tabular}


Table 3. Heat capacities of $\mathrm{A}_{\mathrm{r}}, \mathrm{I}_{2}, \mathrm{I}$, and $\mathrm{CH}_{3} \mathrm{I}$

\begin{tabular}{|c|c|c|c|c|}
\hline \multirow{2}{*}{$\begin{array}{c}\text { Temperature } \\
\mathrm{C}_{\mathrm{K}}\end{array}$} & \multicolumn{4}{|c|}{$\begin{array}{c}\mathrm{C}_{\mathrm{p}}^{\mathrm{O}} \\
\mathrm{cal} / \mathrm{mole}-\mathrm{deg}\end{array}$} \\
\hline & $A_{r}$ & $I_{2}$ & $\mathrm{I}$ & $\mathrm{CH}_{3} \mathrm{I}$ \\
\hline 1000 & 4.968 & 9.06 & 4.970 & 19.15 \\
\hline 1100 & 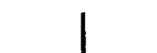 & 9.08 & 4.973 & 19.85 \\
\hline 1200 & & 9.09 & 4.977 & 20.47 \\
\hline 1300 & & 9.11 & 4.984 & 21.00 \\
\hline 1400 & 1 & 9.12 & 4.993 & 21.48 \\
\hline
\end{tabular}

approximately linear over any hundred degree interval, so enthalpies for intermediate temperatures are extracted by linear interpolation. The JANAF (42) workers have also tabulated values for the formation constant of iodine. However, this constant changes rapidly with temperature and is not susceptible to linear interpolation. Thus, it was decided to develop an equilibrium function, $K(T)$, as an exp]icit function of temperature. Lewis and Randall (44, p. 66) have evaluated the function $C_{p}^{o}(T)$ for iodine, from the data of Wagman and Evans (46), in the following manner:

$$
\begin{aligned}
& C_{p}^{0}, I=4.97 \\
& C_{p}^{\circ}, I_{2}=8.94+0.14 \times 10^{-3} \mathrm{~T}-0.17 \times 10^{5} T^{-2} .
\end{aligned}
$$

One may now write:

$$
\begin{aligned}
\Delta \mathrm{H}_{\mathrm{T}}^{\circ} & =\Delta \mathrm{H}_{\mathrm{I}}+\int \Delta \mathrm{c}_{\mathrm{p}}^{\circ} \mathrm{dT} \\
& =\Delta \mathrm{H}_{\mathrm{I}}+\int\left[1.00-0.14 \times 10^{-3} \mathrm{~T}+0.17 \times 10^{5} \mathrm{~T}^{-2}\right] \mathrm{dT},
\end{aligned}
$$


where: $\triangle H_{T}^{\circ}$ is the enthalpy change at temperature $T$ for the formation of two iodine atoms from iodine;

$\Delta \mathrm{H}_{\mathrm{I}}$ is an integration constant.

Using the value of $\Delta \mathrm{H}_{298}^{\mathrm{O}}$ given by Lewis and Randall. (44, p. 672), the result of the integration above is:

$\Delta \mathrm{H}_{\mathrm{T}}^{\mathrm{o}}=35880+1.00 \mathrm{~T}-0.07 \times 10^{-3} \mathrm{~T}^{2}-0.17 \times 10^{5} \mathrm{~T}^{-1}$.

The van't Hoff equation relates the enthalpy change to the equilibrium constant as follows:

$$
\frac{\mathrm{d} \log \mathrm{K}_{\mathrm{T}}}{\mathrm{dT}}=\frac{\Delta \mathrm{H}_{\mathrm{T}}^{\mathrm{o}}}{2.303 \mathrm{RT}^{2}},
$$

where $\mathrm{K}_{\mathrm{T}}$ is the equilibrium constant expressed in units of atmospheres. Integrating Equation 96, one obtains:

$\log \mathrm{K}_{\mathrm{T}}=\mathrm{I}-7844 \mathrm{~T}^{-1}+0.2186 \ln \mathrm{T}-1.53 \times 10^{-5} \mathrm{~T}+1858 \mathrm{~T}^{-2}$

where I represents the integration constant for the indefinite integral. Evaluation of the equilibrium constant at $600^{\circ} \mathrm{K}$ gives a value for I of 3.849 , based on the tabulated equilibrium constants of the JANAF tables (42). Thus, the final form for $\mathrm{K}_{\mathrm{T}}$ is:

$\log \mathrm{K}_{\mathrm{T}}=3.824-7844 \mathrm{~T}^{-1}+0.2186 \ln \mathrm{T}-1.53 \times 10^{-5} \mathrm{~T}+1858 \mathrm{~T}^{-2}$.

This function is in excellent agreement with the values of the JANAF tabulations over the temperature range of interest. 
The degree of dissociation of iodine is a function of temperature and also of pressure, because of the change in mole number. The equilibrium constant may be written as follows:

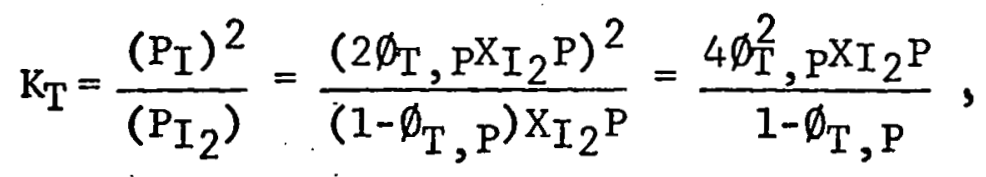

where $P$ is the total pressure of the system. One may now solve the quadratic for $\emptyset_{\mathrm{T}, \mathrm{P}}$, retaining the positive root only, and one obtains:

$$
\emptyset_{\mathrm{T}, \mathrm{P}}=-\frac{\mathrm{K}_{\mathrm{T}}}{8 \mathrm{X}_{\mathrm{I}_{2} \mathrm{P}}}+\left[\left(\frac{\mathrm{K}_{\mathrm{T}}}{8 \mathrm{X}_{\mathrm{I}_{2} \mathrm{P}}}\right)^{2}+\frac{\mathrm{K}_{\mathrm{T}}}{4 \mathrm{X}_{\mathrm{I}_{2} \mathrm{P}}}\right]^{\frac{1}{2}} \text {. }
$$

Thus, one may determine the equilibrium constant at any temperature by Equation 98 . Then, by Equation 100, the degree of dissociation is determined at that same temperature and any given total pressure.

Solution of the shock tube equations was outlined in Section III-B. Equations $76,77,81$, and 87 were readily solved using the tabulated thermodynamic data for the reactants. The dissociation energy, $\Delta \mathrm{H}_{\mathrm{O}}^{\mathrm{O}}$, was taken as 35,560 cal./mole (42). The incident shock wave velocity was calculated from the photograph in Figure 10b. The elapsed time between the first two pressure pulses and the distance separ- 
ating the transducers gave the incident shock velocity to within $2 \%$.

The dissociation of iodine behind the incident shock wave was considered negligible. At incident shock temperatures the equilibrium constant for the dissociation is approximately $10^{-7}$ atmo. Behind the reflected shock the iodine was considered at equilibrium with dissociated iodine atoms. This assumption is based on the shock tube work of Britton et a1. $(47,48)$, who studied the three-body association of iodine atoms diluted in argon. In simplified form, the recombination rate may be written:

$$
k_{R}\left(\frac{c c^{2}}{m o l e^{2}-\sec }\right)=10^{14.87}\left(\frac{1000}{T}\right)^{1.9} .
$$

From the equilibrium constant the second order rate constant for dissociation is found to be:

$$
\mathrm{k}_{\mathrm{D}}\left(\frac{\mathrm{cc}}{\mathrm{mole-sec}}\right)=1.4 \times 10^{10} \mathrm{~T}^{\frac{1}{2}}\left(\frac{\mathrm{U}}{\mathrm{RT}}\right)^{2.83} \exp \left(\frac{-\mathrm{U}}{\mathrm{RT}}\right),
$$

where $U=35,560 \mathrm{cal} . / \mathrm{mole}$. Thus, the rate of production of iodine atoms is given by the following differential equation:

$$
\frac{d(I)}{d t}=2 k_{D}(A)\left(I_{2}\right)-2 k_{K}(A)(I)^{2} \text {, }
$$

where parentheses designate concentrations in units of mole/cc. The solution may be written: 


$$
(I)=\frac{G-K}{4} \frac{1-\exp \left[-G k_{R}(A) t\right]}{1+\frac{G-K}{G+K} \exp \left[-G k_{R}(A) t\right]} \text {, }
$$

where, $\mathrm{K}$ represents the equilibrium constant, $\mathrm{k}_{\mathrm{D}} / \mathrm{k}_{\mathrm{R}}$, and $G=\left[K^{2}+16 K\left(I_{2}\right)_{t=0}\right]^{\frac{1}{2}}$. For al1 the experiments performed on the exchange the equilibrium was effectively established in no more than $15 \%$ of the total reaction time. Thus, the final state behind the reflected shock wave is certainly well represented by the assumption of dissociation equilibrium. However, since the dissociation does occur over a substantial time interval, it is necessary to consider its rate in conjunction with any kinetic scheme for the exchange.

The steady state concentration of methyl radicals was considered low enough to be left out of the enthalpy equations. Mass spectra of shocked $\mathrm{CH}_{3} \mathrm{I}$ samples indicated no unexpected concentrations of side products. Also, using estimates of 29.5 e.u. for the decomposition of methyl iodide and the bond energy of about $55 \mathrm{kcal}$. resulted in the expectation of low steady state concentrations.

\section{B. Treatment of Isotopic Exchange}

The lone parameter necessary to complete the analysis of the isotopic exchange is the reaction time. As before, this 
variable is indirectly determined from the oscilloscope pattern for each experiment. Figure 13 contains an enlargement of the reaction zone corresponding to region 5 in Figure 2 . The gases of interest are those downstream of the ball valve which are removed for analysis. The time interval $t_{\text {obs }}$ is measured from Figure $10 \mathrm{~b}$ as the elapsed time between the second reflected shock pulse and the start of the cooling curve. Since the kinetics of the exchange reaction is complex, it is simpler to obtain a single time average over the reaction zone than to average the extent of reaction over the same zone. One may simply apply the following linear approximation:

$$
t_{\text {av }}=t_{o b s}+\left[\frac{1}{u_{5}}+\frac{1}{a_{5}}\right] x_{0}
$$

where: $x_{0}$ is the distance to the midpoint of the reaction zone;

$u_{5}$ is the velocity of the reflected shock wave;

$a_{5}$ is the velocity of the expansion wave head. The velocity $\mathrm{u}_{5}$ is contained in Figure $10 \mathrm{~b}$ as the time between the last two pressure pulses. The velocity of the expansion wave is the speed of sound in the reaction zone and this is simply determined from the equilibrium state behind the reflected shock. The above approximation causes a very slight underestimate of the reaction time. Coupled with the fact 


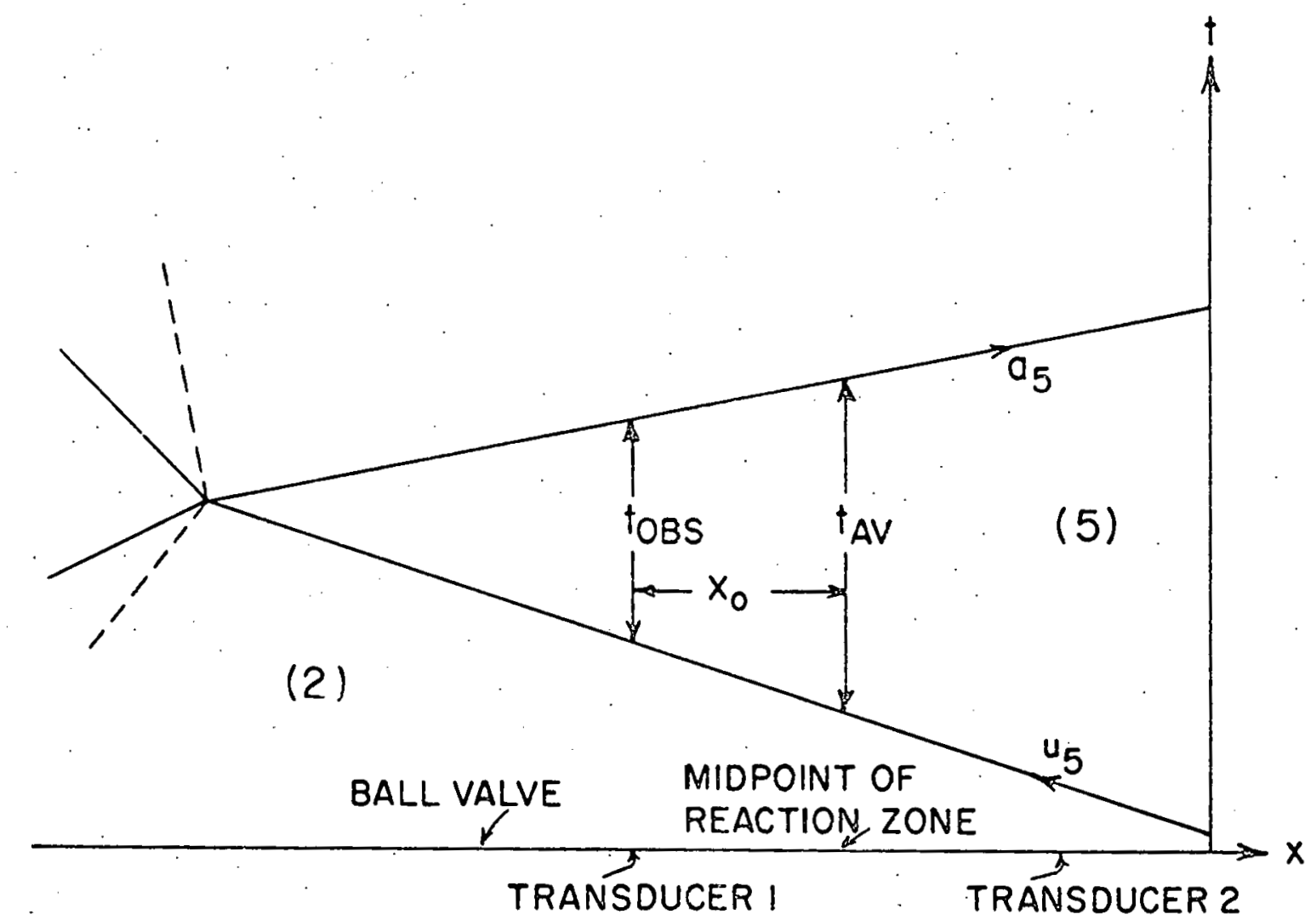

Figure 13. Enlargement of the reaction zone in the shock tube, represented in $x-t$ space 
that the reaction zone expands behind the cooling fan, a correction to the simplistic time average would seem in order. Lifshitz et al. (17) have shown that in some cases the correction to $t_{\text {av }}$ may be as large as $10 \%$. A crude analysis of region 8 in Figure 2, for some typical exchange experiments, indicated that $5 \%$ was a valid estimate for the present case. Since the reaction time can be evaluated to certainly no better than $5 \%$ from Figure $10 \mathrm{~b}$, this correction is questionable.

Although the cooling process is rapid, it may often develop that reaction occurring during the quenching phase is considerable. Thus, for reactions with low activation energies, a positive error in the rate constant would be caused by neglecting the cooling time. In the present case the activation energies were fairly high, the cooling rates were approximately $3.5-4 \times 10^{5} \mathrm{o} / \mathrm{sec}$, and the reaction times were long enough to make this contribution to the reaction time of the order of a few percent. Because of the inherent error of at least $25 \%$ in the determination of the rate constant, this contribution may normally be neglected.

The isotopic exchange reaction can be described by the standard statistical treatment. The mechanism that was found 
to explain the exchange is as follows:

$$
\begin{aligned}
& \mathrm{M}+\mathrm{I}_{2} \underset{\mathrm{r}}{\stackrel{\mathrm{d}}{\rightleftarrows}} 2 \mathrm{I}+\mathrm{M}, \\
& \mathrm{I}+\mathrm{CH}_{3} \mathrm{I} \underset{2}{\stackrel{1}{\rightleftarrows}} \mathrm{CH}_{3}+\mathrm{I}_{2},
\end{aligned}
$$

where $M$ is the inert third body argon.

Let: $\mathrm{U}=$ concentration of active $I$ atoms,

$$
\begin{aligned}
& \mathrm{V}=\text { concentration of active } \mathrm{CH}_{3} \mathrm{I} \text { molecules, } \\
& \mathrm{A}=\text { initial concentration of active } \mathrm{I} \text { atoms in } \mathrm{I}_{2}, \\
& \mathrm{x}=\text { total concentration of } \mathrm{I}_{2} \text { molecules, } \\
& \mathrm{y}=\text { total concentration of } \mathrm{I} \text { atoms, } \\
& \mathrm{z}=\text { total concentration of } \mathrm{CH}_{3} \mathrm{I} \text { molecules. }
\end{aligned}
$$

The rate of formation of active I atoms is given by the following differential equation:

$$
\frac{d U}{d t}=k_{1} y z\left[\frac{A-U-V}{2 x}-\frac{U}{y}\right]+2 k_{d} M \frac{A-U-V}{2 x}-2 k_{r} M_{y}{ }^{2} \frac{U}{y} .
$$

In this equation it must be kept in mind that $\mathrm{x}$ and $\mathrm{y}$ are functions of time as we11 as $U$ and $V$. The concentration of iodine atoms is explicitly given by Equation 104 and the concentration of $\mathrm{I}_{2}$ molecules decreases at half this rate. Equation 106 also contains the assumption that the rate determining step reaches equilibrium very rapidly. This approximation is justified in view of the values of $k_{1}$ and $k_{-1}$ as determined, by Flowers and Benson (9). The1r study indicates the steady 
state concentration of methyl radicals is established in times short compared to the time necessary for complete $\mathrm{I}_{2}$ dissociation. Equation 106 may be rearranged to give the following functional dependence:

$$
\begin{aligned}
\frac{d U}{d t}= & -\left[\frac{k_{1} y z}{2 x}+k_{1} z+k_{d} M+2 k_{r} M_{y}\right] U \\
& -\left[\frac{k_{1} y z}{2 x}+k_{d} M\right] V+\left[\frac{k_{1} y z}{2 x}+k_{d} M\right] A .
\end{aligned}
$$

This equation can be converted into a slightly altered form by converting the concentrations of the active species to specific activities. Thus,

$$
\begin{aligned}
& \mathrm{v} / \mathrm{z}=\mathrm{S}_{\mathrm{CH}_{3} \mathrm{I}}, \\
& \mathrm{U} /(\mathrm{I})_{\mathrm{eq}}=\mathrm{S}_{\mathrm{I}} .
\end{aligned}
$$

Equation 107 now becomes:

$$
\begin{aligned}
\frac{d S_{I}}{d t}= & -\left[\frac{k_{1} y z}{2 x}+k_{1} z+k_{d} M+2 k_{r} M_{y}\right] S_{I} \\
& -\left[\frac{k_{1} y z}{2 x}+k_{d} M\right] \frac{z}{(I)_{e q}} S_{C_{3} I}+\left[\frac{k_{1} y z}{2 x}+k_{d} M\right] \frac{A}{(I)_{e q}}
\end{aligned}
$$

(I) eq may be determined from Equation 104 by letting $t \rightarrow \infty$. Equation 108 still contains unmeasurable quantities and is finally converted by dividing by the equilihrium specific activity, $A /(2 x+y+z)$. The following cquation finally obtains: 


$$
\begin{aligned}
\frac{d F_{I}}{d t}= & -\left[\frac{\bar{k}_{1} y z}{2 x}+k_{1} z+k_{d} M+2 k_{r} M_{y}\right] F_{I} \\
& -\left[\frac{k_{1} y z}{2 x}+k_{d} M\right] \frac{z}{(I)_{e q}} F_{C_{1} I}+\left[\frac{k_{1} y z}{2 x}+k_{d} M\right] \frac{2 x+y+z}{(I)_{e q}}
\end{aligned}
$$

The rate of formation of active $\mathrm{CH}_{3} \mathrm{I}$ molecules is more simply given by the following:

$\frac{d V}{d t}=k_{1} y z\left[\frac{A-U-V}{2 x}-\frac{V}{z}\right]$.

In terms of fraction of exchange Equation 110 may be rewritten:

$$
\begin{array}{r}
\frac{d \mathrm{dFH}_{3} \mathrm{I}}{\mathrm{dt}}=-\frac{\mathrm{k}_{1} \mathrm{y}}{2 \mathrm{x}}(\mathrm{I})_{e q} \mathrm{~F}_{\mathrm{I}}-\left[\frac{\mathrm{k}_{1} \mathrm{yz}}{2 \mathrm{x}}+\mathrm{k}_{1} \mathrm{y}\right] \mathrm{F}_{\mathrm{CH}_{3} \mathrm{I}} \\
+\mathrm{k}_{1} \mathrm{y} \frac{2 \mathrm{x}+\mathrm{y}+\mathrm{z}}{2 \mathrm{x}} .
\end{array}
$$

Equations 109 and 111 are simultaneous linear differential equations in $\mathrm{F}_{\mathrm{CH}_{3} \mathrm{I}}$ and $\mathrm{F}_{\mathrm{I}}$ which cannot be solved explicitly because of the time dependence of the variables $x$ and $y$. However, $\mathrm{F}_{\mathrm{CH}_{3} I}$ can be evaluated as a function of time by numerical integration using the Runge-Kutta method (49). Given two simultaneous differential equations:

$$
\begin{aligned}
& \frac{d x}{d t}=f(t, x, y), \\
& \frac{d y}{d t}=g(t ; x, y),
\end{aligned}
$$

values of $\mathrm{x}$ and $\mathrm{y}$ are determined by the following procedure: 


$$
\begin{aligned}
-k_{1}=f\left(t_{0}, x_{0}, y_{0}\right) \Delta t, \\
k_{2}=f\left(t_{0}+\frac{\Delta t}{2}, x_{0}+\frac{k_{1}}{2}, y_{0}+\frac{\ell_{1}}{2}\right) \Delta t, \\
k_{3}=f\left(t_{0}+\frac{\Delta t}{2}, x_{0}+\frac{k_{2}}{2}, y_{0}+\frac{\ell_{2}}{2}\right) \Delta t, \\
k_{4}=f\left(t_{0}+\Delta t, x_{0}+k_{3}, y_{0}+l_{3}\right) \Delta t, \\
x=\frac{1}{6}\left(k_{1}+2 k_{2}+2 k_{3}+k_{4}\right), \\
\ell_{1}=g\left(t_{0}, x_{0}, y_{0}\right) \Delta t, \\
\ell_{2}=g\left(t_{0}+\frac{\Delta t}{2}, x_{0}+\frac{k_{1}}{2}, y_{0}+\frac{l_{1}}{2}\right) \Delta t, \\
\ell_{3}=g\left(t_{0}+\frac{\Delta t}{2}, x_{0}+\frac{k_{2}}{2}, y_{0}+\frac{l_{2}}{2}\right) \Delta t, \\
\ell_{4}=g\left(t_{0}+\Delta t, x_{0}+k_{3}, y_{0}+\ell_{3}\right) \Delta t, \\
y=\frac{1}{6}\left(l_{1}+2 l_{2}+2 l_{3}+\ell_{4}\right) .
\end{aligned}
$$

By proceeding through to obtain values of $\Delta x$ and $\Delta y$ for given $\Delta t$ and then iterating the new values of $x, y$, and $t$ it is possible to determine $x$ and $y$ at any time with an inhercnt error of $(\Delta t)^{5}$. 
VI. RESULTS AND DISCUSSION

The results of a series of isotopic exchange reactions in the shock tube are tabulated in Table 4 . Column 2 contains the initial pressure of gases in the reactant section. Columns 3 and 4 list the concentrations of $\mathrm{I}_{2}$ and $\mathrm{CH}_{3} \mathrm{I}$ in argon. Reaction temperatures are tabulated in column 5. In column 8 the shock density ratio for each experiment is tabulated. This parameter is useful for evaluating the concentrations of the reactants at reaction conditions. Column 7 contains the fraction of exchange observed in each experiment. Column 9 lists the recorded incident shock speeds.

Column 6 lists the effective dwell times calculated by Equation 105 and corrected as discussed in Section V-B. These times are exceptionally long compared to other shock tube work in a comparable temperature range. This effect is caused principally by the preheating of the driven section of the shock tube. It is also the cause of the slightly lower cooling rates than previously observed. Thus, room temperature experiments result in the temperature jumps being greater than in the present experiments. Correspondingly, the shock waves in the present experiment appear to be travelling slower than would be expected and the resulting reacticn times are greatly 
Table 4. Details of the $\mathrm{CH}_{3} \mathrm{I}_{-} \mathrm{I}_{2}$ isotopic exchange experiments

\begin{tabular}{|c|c|c|c|c|c|c|c|c|c|}
\hline Exp. & $\begin{array}{c}\text { P1 } \\
\mathrm{mm}-\mathrm{Hg}\end{array}$ & $\begin{array}{c}\mathrm{I}_{2} \\
\text { conc. } \\
\text { mole } \%\end{array}$ & $\begin{array}{l}\mathrm{CH}_{3} \mathrm{I} \\
\text { conc. } \\
\text { mole } \%\end{array}$ & $\begin{array}{l}\mathrm{T}_{5} \\
\mathrm{O}_{\mathrm{K}}\end{array}$ & $\begin{array}{l}\text { Dwell } \\
\text { time } \\
\mu \text { sec }\end{array}$ & $\begin{array}{l}\text { Fraction } \\
\text { exchange }\end{array}$ & $\begin{array}{l}\text { Compres- } \\
\text { sion ratio } \\
p_{5} / \rho_{1}\end{array}$ & $\begin{array}{l}\text { Log } k_{1} \\
\text { cc-mole } e^{-1} \\
\text { sec-1 }^{-1}\end{array}$ & $\begin{array}{l}\text { Inc. } \\
\text { shock } \\
\text { speed } \\
10^{-4} \mathrm{x} \\
\mathrm{cm} / \mathrm{sec}\end{array}$ \\
\hline 1 & 220 & .209 & 2.85 & 954 & 2100 & .492 & 4.15 & 9.23 & 5.91 \\
\hline 2 & 224 & .299 & 2.85 & 929 & 2110 & .474 & 4.05 & 9.35 & 5.81 \\
\hline 3 & 187 & .208 & 2.85 & 997 & 1460 & .466 & 4.34 & 9.27 & 6.08 \\
\hline 4 & 239 & .242 & 2.16 & 870 & 2160 & .117 & 3.69 & 9.02 & 5.61 \\
\hline 5 & 235 & .185 & 2.15 & 893 & 2075 & .152 & 3.78 & 9.00 & 5.71 \\
\hline 6 & 235 & .112 & 2.15 & 917 & 2095 & .262 & 3.88 & 9.10 & 5.81 \\
\hline 7 & 215 & .233 & 2.15 & 934 & 1855 & .155 & 3.96 & 8.90 & 5.86 \\
\hline 8 & 197 & .302 & 2.15 & 949 & 1580 & .187 & 4.05 & 9.04 & 5.91 \\
\hline 9 & 236 & .166 & 3.15 & 889 & 2160 & .198 & 3.89 & 8.97 & 5.66 \\
\hline 10 & 237 & .290 & 3.15 & 905 & 2140 & .175 & 3.98 & 8.90 & 5.71 \\
\hline 11 & 228 & .172 & 3.15 & 915 & 1825 & .237 & 4.02 & 9.01 & 5.76 \\
\hline 12 & 235 & .195 & 3.15 & 877 & $2180^{\circ}$ & .135 & 3.84 & 8.8 .2 & 5.61 \\
\hline 13 & 136 & .312 & 3.15 & 1079 & 1100 & .748 & 4.76 & 9.56 & 6.38 \\
\hline 14 & 155 & .308 & 3.15 & 1032 & 1375 & .740 & 4.56 & 9.51 & 6.20 \\
\hline 15 & 158 & .369 & 1.94 & 1105 & 1480 & .787 & 4.66 & 9.53 & 6.50 \\
\hline 16 & 138 & .181 & 1.94 & 1035 & 1570 & .666 & 4.35 & 9.46 & 6.25 \\
\hline .17 & 193 & .186 & 1.94 & 989 & 1720 & .496 & 4.15 & 9.37 & 6.09 \\
\hline 18 & 195 & .198 & 1.94 & 974 & 1745 & .528 & 4.10 & 9.45 & 6.03 \\
\hline 19 & 197 & .236 & 1.94 & 1036 & 1610 & .745 & 4.35 & 9.53 & 6.25 \\
\hline 20 & 198 & .256 & 1.94 & 1005 & 1790 & .622 & 4.24 & 9.44 & 6.14 \\
\hline
\end{tabular}


extended. Problems this effect might cause are discussed shortly.

The data of Table 4 are almost impossible to use to determine the individual reaction orders of the reactants. This difficulty arises because the iodine, introduced as a solid, could not be greatly varied in concentration. The radiation hazard and the low vapor pressure of iodine prevented the use of large concentrations. On the other hand, since the iodine sample had to be weighed analytically, there was a lower limit on the amount that could be used. Also, the reflected shock technique does not allow the same variation of conditions that would be possible with an incident shock alone. This arises from the rule that, in general, it is not possible to bring a gas to a state with a single shock that would be produced by the passage of two shocks.

Thus, the data is best analyzed by comparison with suggested mechanisms. For example, the data could be treated by. the mechanism suggested by Schmied and Fink (11):

$$
\begin{aligned}
& \mathrm{I}-\mathrm{I} * \mathrm{CH}_{3} \mathrm{I}=\mathrm{CH}_{3} \mathrm{I} * \mathrm{I}-\mathrm{I}, \\
& \mathrm{k}\left(\frac{\mathrm{cc}}{\mathrm{mole}-\mathrm{sec}}\right)=2.5 \times 10^{6} \exp (-9000 / \mathrm{RT}) .
\end{aligned}
$$

However, this mechanism was found to predominate at temperatures approximately $600^{\circ} \mathrm{K}$ lower than those studied herein. 
One certainly would not expect a mechanism of such low activation energy to predominate at $900^{\circ} \mathrm{K}$. The treatment of the data gave absolutely no agreement with Equation 112. Although the data did not display bad scatter for this mechanism, the temperature dependence was large and the pre-exponential factor was several orders of magnitude larger than could be expected from simple collision theory.

Another possibility appeared to be the bimolecular decomposition of methyl iodide:

$$
\mathrm{M}+\mathrm{CH}_{3} \mathrm{I} \rightleftharpoons \mathrm{M}+\mathrm{CH}_{3}+\mathrm{I} \text {. }
$$

This mechanism was ruled out for several reasons. Primarily, the consistency of the data was very poor. Secondly, using the approximate bond energy of the $\mathrm{C}-\mathrm{I}$ bond, $55 \mathrm{kcal}$., for the activation energy again resulted in a pre-exponential factor much larger than could be expected from collision theory. Since, in general, the fractions of exchange were lower than expected, it is unlikely that this higher activation energy process is contributing significantly.

A third mechanism, a combination of the results of Flowers and Benson (9) and Britton et al. $(47,48)$, is repeated here:

$$
\mathrm{M}+\mathrm{I}_{2} \underset{\mathrm{r}}{\stackrel{\mathrm{d}}{\rightleftarrows}} \mathrm{M}+2 \mathrm{I},
$$




$$
\begin{aligned}
& \mathrm{I}+\mathrm{CH}_{3} \mathrm{I} \underset{2}{\stackrel{1}{\rightleftarrows}} \mathrm{CH}_{3}+\mathrm{I}_{2} \\
& \mathrm{k}_{\mathrm{d}}\left(\frac{\mathrm{cc}}{\mathrm{mole-sec}}\right)=1.4 \times 10^{10}(\mathrm{~T})^{\frac{1}{2}}\left(\frac{35560}{\mathrm{RT}}\right)^{2.83} \exp \left(\frac{-35560}{\mathrm{RT}}\right) \\
& \mathrm{k}_{\mathrm{r}}\left(\frac{\mathrm{cc^{2 }}}{\mathrm{mole} \mathrm{e}^{2}-\mathrm{sec}}\right)=10^{14.87}\left(\frac{1000}{\mathrm{~T}}\right)^{1.9}, \\
& \mathrm{k}_{1}\left(\frac{\mathrm{cc}}{\mathrm{mole}-\mathrm{sec}}\right)=10^{14.2} \exp \left(-\frac{20000}{\mathrm{RT}}\right), \\
& \mathrm{k}_{2}\left(\frac{\mathrm{cc}}{\mathrm{mole}-\mathrm{sec}}\right)=10^{12.9} \exp \left(-\frac{400}{\mathrm{RT}}\right)
\end{aligned}
$$

Using the numerical integration procedure outlined in the last section, values of $k_{1}$ were found for each experiment and they are tabulated in column 8 of Table 4. These values are plotted in Figure 14 along with the solid line representing Equation 115, found by Flowers and Benson, and its extrapolation to high temperatures. The points are in close agreement with Equation 115 although they generally give a lower value of $k_{1}$. Flowers and Benson suggested that the values given in Equation 115 represented an upper limit and that the preexponential factor was slightly in excess of ccllision frequencies. The overall error involved in the present experimental determination of $k_{1}$ is probably of the order of $25-35 \%$. Thus, the difference noted in Figure 14 is probably slightly 


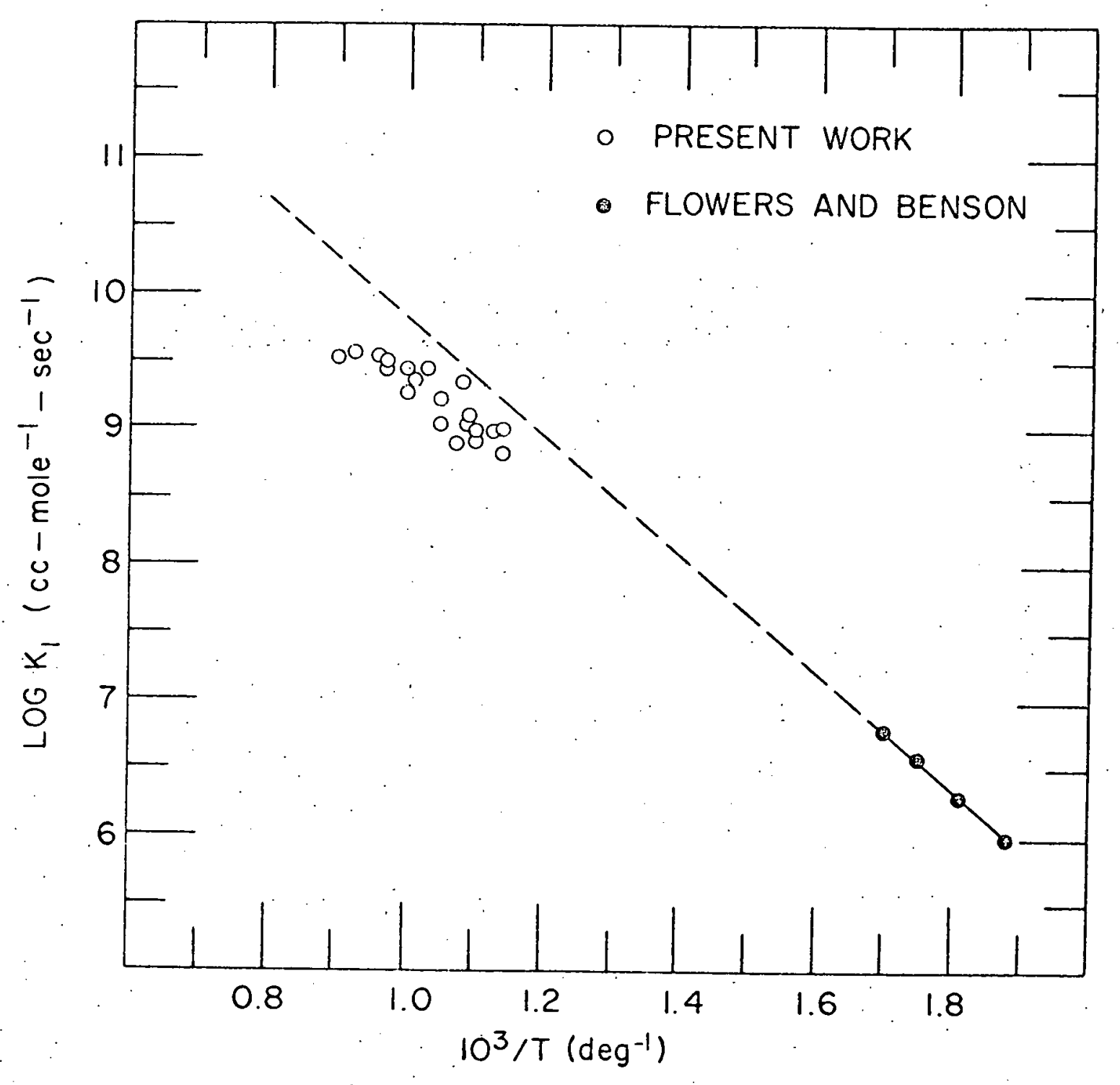

Figure 14. Arrhenius plot for the CH3I-I2 exchange. Open circles from present work. Dotted line represents extrapolation from Flowers and Benson (9), their results denoted by closed circles 
exaggerated. However, the values determined from the shock tube experiment are consistently low and deserve explanation. In most shock tube work cooling at the walls is not considered important to consider. Reaction times are short and one may expect rather small temperature and pressure effects. Also, tube diameters, when possible, are large such that surface to volume ratios are small. Heat conduction is thus confined to a thin layer of gas at the surface and hence confined to a small volume of gas. In the present case the tube diameter was only $2.54 \mathrm{~cm}$. and contact times were never below a millisecond. An in depth analysis is pointless since heat conduction in a system such as a shock tube is a poorly developed subject. It is not inconceivable that the gas temperature drops $20-25^{\circ} \mathrm{K}$ during the contact times in the present experiments. Thus, it must be concluded that the pre-exponential factor for the rate determining for the exchange would be in the range $10^{14.1}-10^{14.2}$. The activation energy is in close agreement with the $20 \mathrm{kcal}$. found by Flowers and Benson.

It is at once apparent that the same results would be obtained if the rate determining step were chosen to be the $\mathrm{S}_{\mathrm{N}} 2$ inversion suggested by Clark et al. (6). Although it is impossible to directly distinguish between these two mechan- 
isms, several experiments have recently shown that iodine replacement reactions depend on the establishment of iodine equilibrium succeeded by the formation of free radical inte:mediates. Several of these cases are tabulated in Table 5 .

Table 5. Iodine reactions with free radical intermediates

\begin{tabular}{|c|c|c|}
\hline Overall reaction & Mechanism & Reference \\
\hline $\mathrm{HI}+\mathrm{CH}_{3} \mathrm{I} \rightleftharpoons \mathrm{I}_{2}+\mathrm{CH}_{4}$ & $\begin{aligned} \mathrm{I}_{2} & \rightleftharpoons 2 \mathrm{I} \\
\mathrm{I}+\mathrm{CH}_{3} \mathrm{I} & \rightleftarrows \mathrm{CH}_{3}+\mathrm{I}_{2} \\
\mathrm{HI}+\mathrm{CH}_{3} & \rightleftharpoons \mathrm{CH}_{4}+\mathrm{I}\end{aligned}$ & 9 \\
\hline $\mathrm{I}_{2}+\mathrm{CH}_{4} \rightleftharpoons \mathrm{HI}+\mathrm{CH}_{3} \mathrm{I}$ & $\begin{aligned} \mathrm{I}_{2} & \rightleftharpoons 2 \mathrm{I} \\
\mathrm{I}+\mathrm{CH}_{4} & \neq \mathrm{CH}_{3}+\mathrm{HI} \\
\mathrm{I}_{2}+\mathrm{CH}_{3} & \rightleftharpoons \mathrm{CH}_{3} \mathrm{I}+\mathrm{I}\end{aligned}$ & 50 \\
\hline $\mathrm{I}_{2}+\mathrm{CF}_{3} \mathrm{H} \rightleftharpoons \mathrm{HI}+\mathrm{CF}_{3} \mathrm{I}$ & $\begin{aligned} \mathrm{I}_{2} & \geq 2 \mathrm{I} \\
\mathrm{I}+\mathrm{CF}_{3} \mathrm{H} & \rightleftharpoons \mathrm{CF}_{3}+\mathrm{HI} \\
\mathrm{I}_{2}+\mathrm{CF}_{3} & \rightleftharpoons \mathrm{CF}_{3} \mathrm{I}+\mathrm{I}\end{aligned}$ & 51. \\
\hline
\end{tabular}

In conclusion, it can definitely be stated that the high temperature $\mathrm{CH}_{3} \mathrm{I}-\mathrm{I}_{2}$ homogeneous exchange was observed in the absence of surface reaction. It would be expected that at higher temperatures than those studied here the decomposition of methyl iodide would itself become the predominant route 
for the exchange. This might be a singular method for studying the decomposition without extensive formation of organic side products. Once again, surface reactions that are commonplace with the alkyl iodides would be eliminated in the shock tube. Any contribution to the literature of bond energies or mechanisms for decomposition of the lower alkyl iodides would be a welcome addition. 


\section{SUMMARY}

The shock tube study of the isotopic exchange reaction

$$
\mathrm{I}-\mathrm{I} *+\mathrm{CH}_{3} \mathrm{I} \rightleftharpoons \mathrm{CH}_{3} \mathrm{I} *+\mathrm{I}-\mathrm{I}
$$

was found consistent with a rate determining step first order in methyl iodide concentration and first order in iodine atom concentration. This step was preceded by the rapid dissociation of molecular iodine. The rate constant for the exchange step was found to be:

$$
k\left(\frac{c c}{\text { mole-sec }}\right)=10^{13.9} \exp \left(-\frac{20000}{R T}\right) .
$$

This value is slightly below what might be expected from collision theory and a value of $14.1-14.2$ is preferred for the Arrhenius factor. The exchange is believed to proceed by formation of methy1 radicals rather than the $\mathrm{S}_{\mathrm{N}} 2$ inversion of methyl iodide.

The isotopic exchange was homogeneous and uncomplicated by surface reaction frequently observed in iodine systems. Methyl iodide decomposition was not a contributing factor in the temperature and time range of the present study. Similarly, bimolecular collisions between molecular iodine and methy 1 iodide was ruled out as a possible exchange mechanism on the basis of theoretical collision frequencies. 


\section{LITERATURE CITED}

1. Bodenstein, M., Z. physik. Chem., 13, 56 (1894).

2. Bodenstein, M., Z. physik. Chem., 22, 1 (1897).

3. Bodenstein, M., Z. physik. Chem., 29, 295 (1899).

4. Ogg, R. A., Jr., J. Am. Chem. Soc., 56, 526 (1934).

5. Ogg, R. A., Jr. and Polanyi, M., Trans. Far. Soc., 31, 482 (1935).

6. Clark, D., Pritchard, H. O., and Trotman-Dickenson, A. F., J. Chem. Soc. (London), 1954, 2633 (1954).

7. Benson, S. W. and O'Neal, E., J. Chem. Phys., 34, 514 (1961).

8. Sullivan, J. H., J. Phys. Chem., 65, 722 (1961).

9. Flowers, M. C. and Benson, S. W., J. Chem. Phys., 38, 882 (1963).

10. Sullivan, J. H., J. Chem. Phys., 46, 73 (1967).

11. Schmied, H. and Fink, R. W., J. Chem. Phys., 27, 1034 (1957).

12. Earnshaw, S., Trans. Roy. Soc. (London), 150, 133 (1860).

13. Viei11e, P., Compt. Rend., 129, 1228 (1899).

14. Carrington, T. and Davidson, N., J. Phys. Chem., 57, 418 (1953).

15. Kevorkian, V., Heath, C. E., and Boudart, M., J. Phys. Chem., 64, 964 (1960).

16. Glick, H. S., Squire, W., and Hertzberg, A., Symposium (International) on Combustion, 5; 393 (1955).

17. Lifshitz, A., Bauer, S. H., and Resler, E. L., J. Chem. Phys., 38, 2056 (1963). 
18. Glass, I. I. and Hall, J. G. Shock Tubes. In Johns Hopkins University. Applied Physics Laboratory. Handbook of Supersonic Aerodynamics. Volume 6. Section 18. Silver Springs, Maryland, Applied Physics Laboratory, John Hopkins University. 1959.

19. Lifshitz, A., Carrol1, H. F., and Bauer, S. H., J. Chem. Phys., 39, 1661 (1963).

20. Bradley, J. N. Shock Waves in Chemistry and Physics. New York, N.Y., John Wiley and Sons, Inc. 1962.

21. Greene, E. F. and Toennies, J. P. Chemical Reactions in Shock Waves. London, England, Edward Arnold (Publishers), Ltd. 1964 .

22. Walsh, J. M. and Rice, M. H., J. Chem. Phys., 26, 815 (1957).

23. Rice, M. H. and Walsh, J. M., J. Chem. Phys., 26, 824 (1957).

24. David, H. G. and Hamman, S. D., Trans. Far. Soc., 5ㅁ, 72 (1959).

25. Greene, E. F., J. Am. Chem. Soc., 76, 2127 (1954).

26. Palmer, H. B. and Hornig, D. F., J. Chem. Phys., 26, 98 (1957).

27. Klepeis, J. E. A Gasdynamic Chemical Quench Tube. Unpublished M.S. thesis. Ithaca, N.Y., Lihrary, Cornell University. 1961.

28. Gaydon, A. G. and Wolfhard, H. G. Flames, Their Structure, Radiation and Temperature. 2nd ed. New York, N.Y., Macmillan Co. 1960.

29. Fairbairn, A. R. and Gaydon, A. G., Proc. Roy. Soc. (London), A239, 464 (1957).

30. Shunk, R. A., Dranetz, A. I., and Budenstein, P. P., Rev. Sci. Instr., 24, 1069 (1953). 
31. Knight, H. T., Rev. Sci. Instr., 29, 174 (1958).

32. Johnson, C. D. and Britton, D., J. Chem. Phys., 38, 1455 (1963).

33. Brabbs, T. A., Zlatarich, S. A. and Belles, F. E., J. Chem. Phys., 33, 307 (1960).

34. Skinner, G. B., J. Chem. Phys., 31, 268 (1959).

35. Strehlow, R. A. and Case, C. T., J. Chem. Phys., 35, 1506 (1961).

36. Bradley, J. N. and Kistiakowsky, G. B., J. Chem. Phys., $\underline{35}, 256$ (1961).

37. Wright, J. K. Shock Tubes. New York, N.Y., John Wiley and Sons, Inc. 1961.

38. Liepmann, H. W. and Roshko, A. Elements of Gasdynamics. New York, N.Y., John Wiley and Sons, Inc. 1957.

39. Eskinazi, S. Vector Mechanics of Fluids and Magnetofluids. New York, N.Y., Academic Press, Inc. 1967.

40. Landau, L. D. and Lifshitz, E. M. Fluid Mechanics. (Translated from the Russian by Sykes, J. B. and Reid, W. H.) Reading, Mass., Addison-Wesley Publishing Co.

41. Harris, G. M. and Willard, J. E., J. Am. Chem. Soc., 76, 4678 (1954).

42. Dow Chemical Company. Thermal Research Laboratory. JANAF Thermochemical Tables. Midland, Mich., Author. 1965.

43. Sponer, H. Molekülspektren. Berlin, Germany, J. Springer. 1935.

44. Lewis, $G$. N. and Randa11, M. Thermodynamics: 2nd ed. Revised by Pitzer, K. S. and Brewer, L. New York, N.Y. McGraw-Hil1 Book Co., Inc. 1961. 
45. Edgeîl, W. F. and Glockler, G., J. Chem. Phys., 9 , 484 (1941).

46. Wagman, D. D. and Evans, W. H: Selected Values of Chenical Thermodynamic Properties, Series III Compilation. Washington, D.C., National Bureau of Standards. 19471956.

47. Britton, D., Davidson, N., Gehman, W., and Schott, G., J. Chem. Phys., 25, 804 (1956).

48. Britton, D., Davidson, N., and Schott, G., Disc. Far. Soc., 17, 58 (1954).

49. Scarborough, J. B. Numerical Mathematical Analysis. 5th ed. Baltimore, Md., The Johns Hopkins Press. 1962.

50. Goy, C. A. and Pritchard, H. 0., J. Phys. Chem., $\underline{69}, 3040$ (1965).

51. Goy, C. A., Lord, A., and Pritchard, H. O., J. Phys. Chem., 71, 1086 (1967). 


\section{ACKNOWLEDGMENT}

The author wishes to express his gratitude to.Dr. Don.S. Martin,. Jr., for his guidance, interest, encouragement, and infinite patience; to W. Lankford and E. McKenna for their cooperation in nursing the shock tube into existence; and to G. Junk for performing mass spectral analyses of shock tube samples .

The author also wishes to thank the many members of his group, especially L. Hunter, for giving their time for discussion and suggestions.

Finally, the author wishes to thank his wife, Bethann, for reading the manuscript and for helping a runaway train get back on the track. 


\section{APPENDIX}

The method of characteristics, or Riemann invariants, is a useful subject in the study of any fluid flow. The technique is a result of the basic laws of fluid motion. To begin, one must define the following function:

$$
f(p) \equiv \int_{\rho_{o}}^{\rho} a_{p}^{d p}
$$

As a consequence of the definition, the following results may be written:

and

$$
\begin{aligned}
& \frac{\partial f}{\partial x}=\frac{a}{\rho} \frac{\partial \rho}{\partial x}, \\
& \frac{\partial f}{\partial t}=\frac{a}{\rho} \frac{\partial \rho}{\partial t},
\end{aligned}
$$

$$
\frac{\partial p}{\partial x}=a^{2} \frac{\partial \rho}{\partial x}=\rho a \frac{\partial f}{\partial x} \text {. }
$$

Applying these results to Equation 1, rewritten for onedimensional flow, and multiplying by $a / p$, one finds:

$$
\frac{\partial f}{\partial t}+a \frac{\partial u}{\partial x}+u \frac{\partial f}{\partial x}=0
$$

Similarly, Equation 4 yields:

$$
\frac{\partial u}{\partial t}+u \frac{\partial u}{\partial x}+a \frac{\partial f}{\partial x}=0
$$

If one now takes the two possible linear combinations of Equalions $A-5$ and $A-6$, the following equation obtains:

$$
\frac{\partial}{\partial t}(f \pm u)+(u \pm a) \frac{\partial}{\partial x}(f \pm u)=0
$$


The Riemann invariants, $f \pm u$, are constants along curves. in $x-t$ space with slopes $u \pm a$. The curves along which the invariants are constant are referred to as characteristics. P and $Q$ are symbolically used to denote the invariants $f+u$ and $f$ - $u$, respectively. Using Equation 25, Equation A-1 is exactly integrable, and taking the reference density to be zero one finds:

$$
f=\frac{2 a}{\gamma-1} \text {. }
$$

Now, consider the left-facing rarefaction wave of Figure 15. The wave travels into a region which is initially at rest. The value of the invariant $\mathrm{P}$ is constant, although the characteristic curve slopes through the rarefaction wave. The following condition may be written:

$$
P=\frac{2 a_{1}}{\gamma-1}=\frac{2 a}{\gamma-1}+u
$$

at any point in the rarefaction wave, on the line of slope $u+a$. Thus, one may write:

$$
u=\frac{2 a_{1}}{\gamma-1}-\frac{2 a}{\gamma-1}=\frac{a_{1}\left(1-a / a_{1}\right)}{\gamma^{\beta}}
$$

A rarefaction wave, like any small perturbation in a fluid, causes an adiabatic transition. As a result, one may write:

$$
\frac{a}{a_{1}}=\left(\frac{p}{p_{1}}\right)^{\beta}
$$




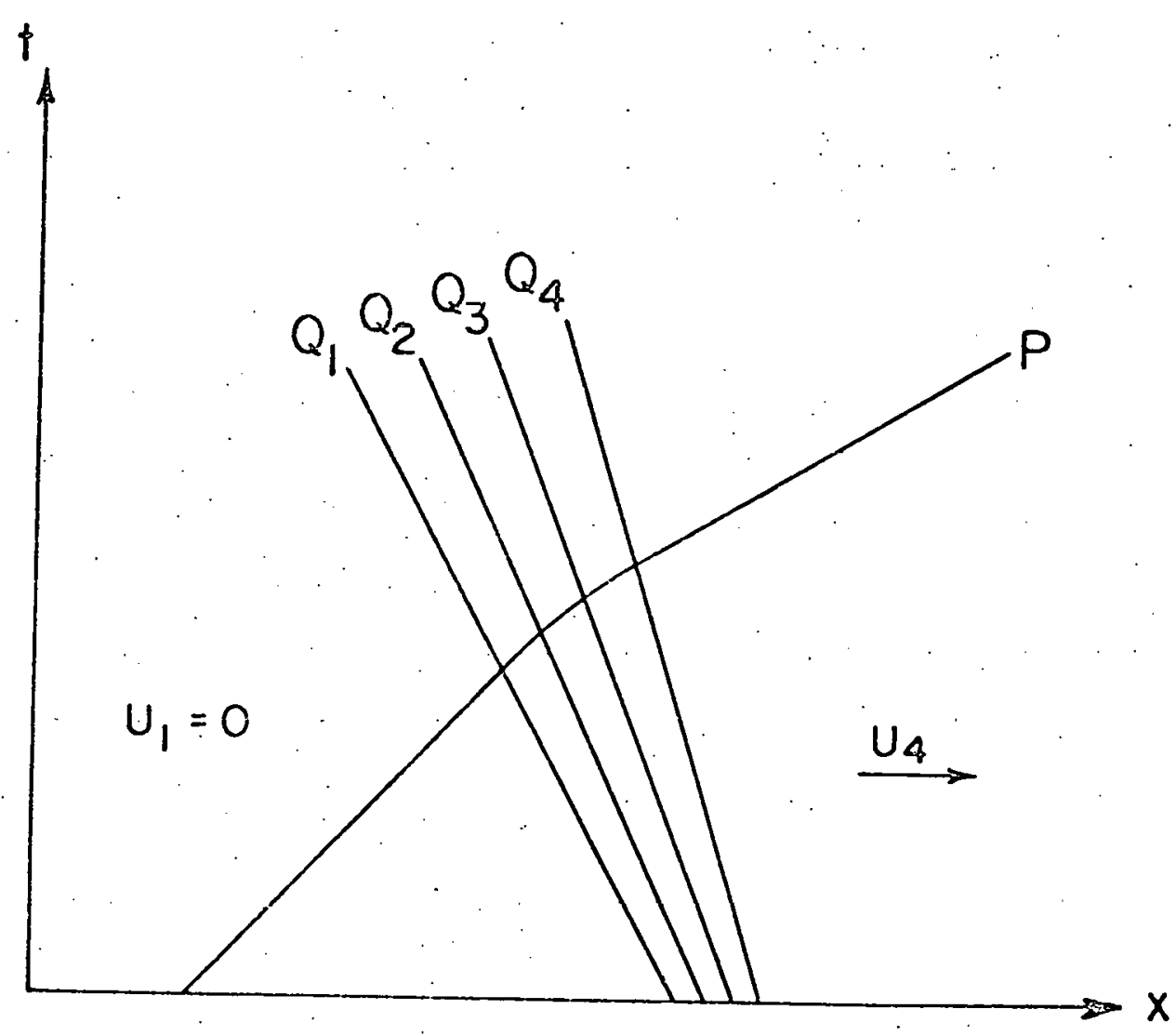

Figure 15. Left-facing rarefaction wave represented in $x-t$ space 
Equation $A-10$ then takes the final form:

$$
u=\frac{a_{1}}{\gamma \beta}\left[1-\left(\frac{p}{p_{1}}\right)^{\beta}\right] \text {. }
$$

Several important properties of the fluid motion may be extracted from Equation $\mathrm{A}-12$. Since the pressure ratio $\mathrm{p} / \mathrm{p}_{1}$ is less than unity at any point in the wave, Equation A-12 indicates the fluid flow is in the direction opposite from that of the wave motion. Also, since weak disturbances propagate at the speed of sound, the head of the rarefaction wave travels at the sound speed of gas 1 while the tail travels at the sound speed of gas 4. Thus, one sees that an expansion wave fans out with time. An analysis of $u \pm$ a through the wave would give the slopes of the $P$ and $Q$ lines as demonstrated in Figure 15.

If one performs the same analysis on a left-facing compression wave, Equation A-12 would again be the result. However, $\mathrm{p} / \mathrm{p}_{1}$ would always be larger than unity and fluid flow would thus be in the same direction as the wave motion. The $P$ line would curve through the compression wave, but in the opposite direction of Figure 15. Also, the Q lines would be found to be convergent. In fact, at the point at which they 
converge, - a shock front would be formed. This sequence of events closely approximates the nonideal formation of a shock wave by a bursting diaphragm. 